\title{
Alteraciones climáticas, haciendas y vida social de los negros esclavos y libertos en Piura: 1791-1823
}

Recibido: 09/10/19

Aprobado: 09/11/19

\author{
César Espinoza Claudio \\ Universidad Nacional Mayor de San Marcos \\ cespinozac@unmsm.edu.pe
}

\begin{abstract}
RESUMEN
A partir de varios procesos judiciales ubicados en el Archivo Regional de Piura, sobre el impacto y la destrucción de los campos de cultivo y de pastoreo de haciendas y tierras de labranza por la fuerza de las lluvias e inundaciones y de los ciclos de años secos, se muestra la existencia y la dinámica social de la población negra que habita dentro y fuera de la ciudad de San Miguel de Piura en un contexto político de crisis de la dominación virreinal. Se examina la resistencia social de una población que sobrevive en las orillas de los ríos de la costa y la sierra de Piura, convertidos en labradores o colonos para producir granos y carnes para el abasto de la ciudad de Piura. Se analiza la constitución del cimarronaje y los palenques en los montes de algarrobo y zapote en los alrededores de la ciudad y los interiores de la gran propiedad terrateniente. En suma, se detalla la compleja vida social de los negros esclavos y libertos frente a los ciclos de sequías y lluvias, incendios y esterilidades en las tierras de haciendas ubicadas entre Olmos y Tambogrande, y entre Pabur y la ciudad de San Miguel de Piura entre 1791-1823.
\end{abstract}

Palabras clave: Piura, esclavos, negros, lluvias, cimarronaje.

\section{Climate alterations, Lords of the land, and social life of Black frees and slaves in Piura: 1791-1823}

\begin{abstract}
This research presents the social dynamics of the existing black population that inhabited inside and outside the city of San Miguel de Piura, in a context of the political crisis of the viceregal domination. We reviewed several judicial processes located in the Regional Archive of Piura, about the intensity of the rains and floods, the cycles of dry years, and their destructive impacts on the fields of cultivation and grazing, belonging to the Haciendas and farmland. We examine the social resistance of a population that survived on rivers banks from the coast and the highlands of Piura, turned into farmers or settlers, to produce grains and meats for the supply of Piura's city. We analyze the conformation of Marronage and Palenques in the carob and sapote mountains surrounding the city and within large landowner's estates. Finally, we detailed the complex social life of Black frees and slaves, who were facing drought and rain cycles, fires and sterilities, in Haciendas lands located between Olmos and Tambogrande, and also between Pabur and the city of San Miguel de Piura during 1791-1823.
\end{abstract}

KeYwords: Piura, slaves, Black people, rain, Marronage. 


\section{Palenques y Cimarronaje: procesos de resistencia al sistema colonial esclavista en los médanos y quebradas de algarrobo en Piura}

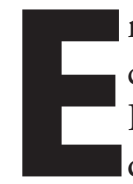
n la región de Piura falta estudiar las lógicas del cimarronaje y la constitución de los Palenques en el piedemonte y la cordillera de Ayabaca y Guancabamba. Frente al sistema colonia virreinal se construyó un movimiento de resistencia de los esclavos negros y libertos en una región azotada permanentemente por ciclos de alteraciones climáticas (Lorenzo Huertas 2016: 198-206 y 304. Lizardo Seiner 2002 y 2001: 1-18. Susana Aldana 1996: 167-194)

Durante el transcurso de tres siglos la población negra se asentó al interior de la ciudad y el campo de la costa de Piura y también en los valles quechuas y yungas de Ayabaca y Guarmaca a finales del siglo XVIII. Los negros esclavos se enfrentaron a las reformas borbónicas. Practicaron la fuga individual y colectiva buscando la autonomía social y territorial. Los estudios sobre el cimarronaje y el bandolerismo rural y urbano, y la migración forzada hacia la sierra de Piura es un tema poco estudiado por los historiadores locales y nacionales (César Espinoza 2019; 2019a; 2017 y 2016).

La visita y las reformas políticas realizadas por el obispo Martínez Compañón confirman la existencia de numerosas agrupaciones de familias e individuos negros en calidad de esclavos y libertos al interior de las haciendas y estancias costeńas y serranas que se desplazaron temporalmente entre los valles costeños e interandinos. Los ciclos agrarios y temporales estaban atados a los ciclos climáticos y geográficos que usaban las diversas castas poblacionales para autogenerar y reproducir sus economías de autoconsumo y de mercado regional. Es falsa e insidiosa la idea de que esta población de origen africano vivía atrapada por la ociosidad y el alcoholismo, la violencia armada y el robo cotidiano (Campos y Fernandez de Sevilla 2014: 165-212. Fermín del Pino 2012: 421-508).

$\mathrm{Al}$ interior de los Partidos y las parroquias rurales se han organizado una variedad de asentamientos poblacionales que van desde los microcaserios y pequeńos palenques asentados a orillas de los afluentes de los ríos buscando explotar pequeñas parcelas de tierras y campos de pastoreo.
En el valle de La Chira se transitó del régimen agrario de la hacienda al dominio del gran latifundio de las tierras de Tangarará. La familia Sojo iniciará la expansión de sus fronteras territoriales desde Amotape hasta Poechos a finales del siglo XvII. Al interior de esta gran propiedad rural emergieron varios asentamientos poblacionales sometidos a la lógica de la economía terrateniente que explotaba al colono campesino, al peón asalariado y al negro esclavo y liberto. En la frontera oriental de esta gran propiedad yunga se organizaron varios asentamientos poblacionales multiétnicos destacando a finales del siglo XvIII el centro poblado de Querecotillo.

A comienzos del siglo XIX se fortalecerá la economía campesina y la pequeńa propiedad parcelaria en dirección a Marcavelica y a la formación de un pequeño núcleo urbano entre Tillopaira y el sitio de La Punta. Hacia estos puntos de concentración poblacional migraron y se asentaron numerosas familias de esclavos y de negros libertos. Se trata entonces de la organización de una compleja y diversa microterritorialidad en la que están asentados cientos y miles de familias que vivirán al interior de un espacio geográfico practicando el colonato campesino, el cimarronaje y el bandolerismo como expresiones sociales de un movimiento de autonomía social y de apropiación y de organización de un territorio autónomo que asumirá en 1840 la forma de la creación de una unidad distrital dependiente de Sullana y Payta (César Espinoza 2019: 195-222).

El valle de La Chira es un espacio geográfico organizado primero en encomiendas para luego funcionar bajo el sistema de la hacienda para producir algodón y negociar con el engorde de ganado vacuno y caprino orientado a un mercado local y regional. La geografía y la economía agraria y pecuaria se fusionarán con el trabajo temporal de los colonos campesinos indígenas y de los negros esclavos y de cimarrones produciendo un tipo de asentamiento territorial disperso al interior de la gran propiedad rural de Tangarará, Máncora y Tumbes (César Espinoza 2013: 339-368).

A mediados del siglo XviII se organizó otra gran hacienda estanciera, Morropón, ubicado en el piedemonte cordillerano junto a otras propiedades rurales vecinas como Yapatera y Sol Sol, Guangalá y Tambogrande, unidades ganaderas claves para la producción combinada de la caña de azúcar y el engorde de ganado cabrío que terminaran sus grasas y 


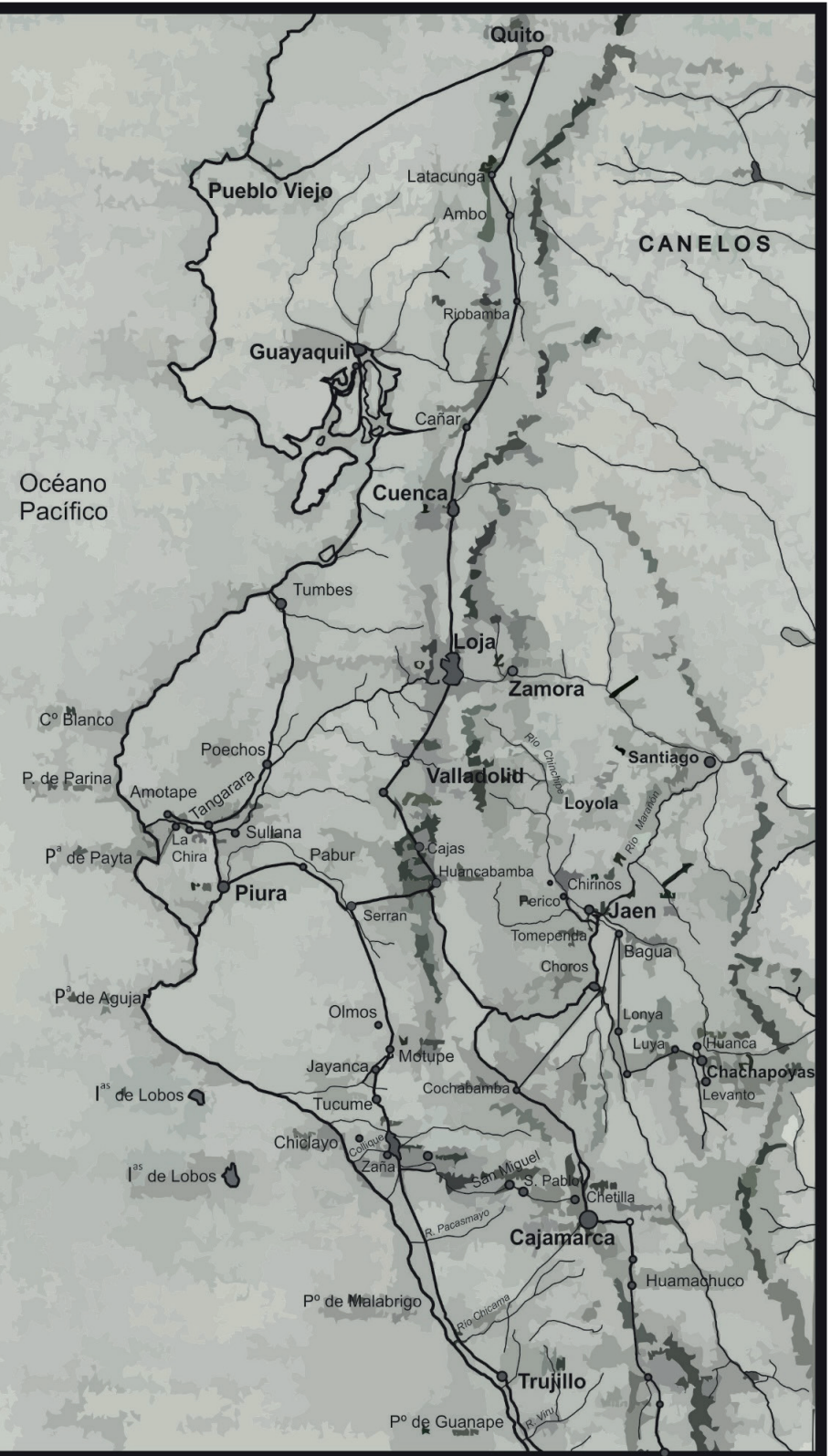

Mapa de ríos y caminos en el Virreinato y comienzos de la República del Perú. Reelaborado por Pavel Espinoza Ortega. Fuente consultada : Hocquenghem, Anne-Marie. «Los españoles en los caminos del extremo norte del Perú en 1532", en Bulletin de L'institut francais d'études andines. IFEA, Lima, 23 (1), p. 8. Fig. 1.

sebos procesados en las tinas de jabones y cordobanes instalados en las orillas vecinas del río y las tierras de Ejidos de la ciudad de SM de Piura. En efecto, al interior de las grandes estancias ganaderas se van asentando también pequeños núcleos poblacionales de gente mestiza blanca y serrana junto a los negros esclavos y libertos que trabajaran en las tierras de ori- llas de los ríos afluentes que desembocan en el rio Piura. Al interior de estos grandes espacios de quebradas y de planicies desérticas vivirán los negros cimarrones en medio de palenques y junto a los bandoleros rurales que suben y bajan por la cordillera y la frontera con Loja y Cuenca. A finales de este siglo, la familia limeña de los Fernández de Paredes controla y explota estas dos grandes propiedades terratenientes, Tangarará en el valle de La Chira y Morropón en el piedemonte andino cercano al valle serrano de Guancabamba (Elizabeth Hernández 2007: 361-391 y César Espinoza 2016 y 2016a).

\section{La dinámica social de los afrodescendientes durante la época colonial en la región de Piura}

Desde el último tercio del siglo Xvi se registró la presencia de los negros esclavos en la ciudad de San Miguel de Piura y en el puerto de San Francisco de la Buena Esperanza de Payta. En ambos núcleos urbanos residen los encomenderos y un grupo de comerciantes españoles que se dedicaron al tráfico de negros esclavos procedentes del Africa y de Panamá. Los encomenderos y los curas son los principales agentes económicos vendedores y revendedores de hombres y mujeres que llegaron por la ruta del mar procedentes de la ciudad de Panamá para desde la ciudad de Piura utilizar el camino o ruta terrestre y ser transportados y rematados en Saña, Trujillo y Lima. Un núcleo pequeńo de comerciantes asentados en Piura se dedicará a este tipo de tráfico de gentes para acumular dinero y luego comprar tierras y solicitar cargos burocráticos al rey de España. Podemos postular la tesis de que con las reformas borbónicas se incrementó el tráfico y el número de negros que llegaron desde Panamá para introducirse a las ciudades de la costa norte y asentarse al interior de las haciendas algodoneras y azucareras de la costa norte del Perú (Juan José Vega 1993. Pavel Elías Lequernaqué 2004. Lorenzo Huertas 1991).

Entre Payta y Catacaos, pero también entre Payta y Tangarará-Poechos se distribuyó la población esclava para laborar las tierras de estos valles en calidad de peones asalariados y el trabajo de servicio doméstico y de seguridad de las familias ricas y blancas de Piura. La zona geográfica que concentró a la población afrodescendiente se encuentra entonces entre la 


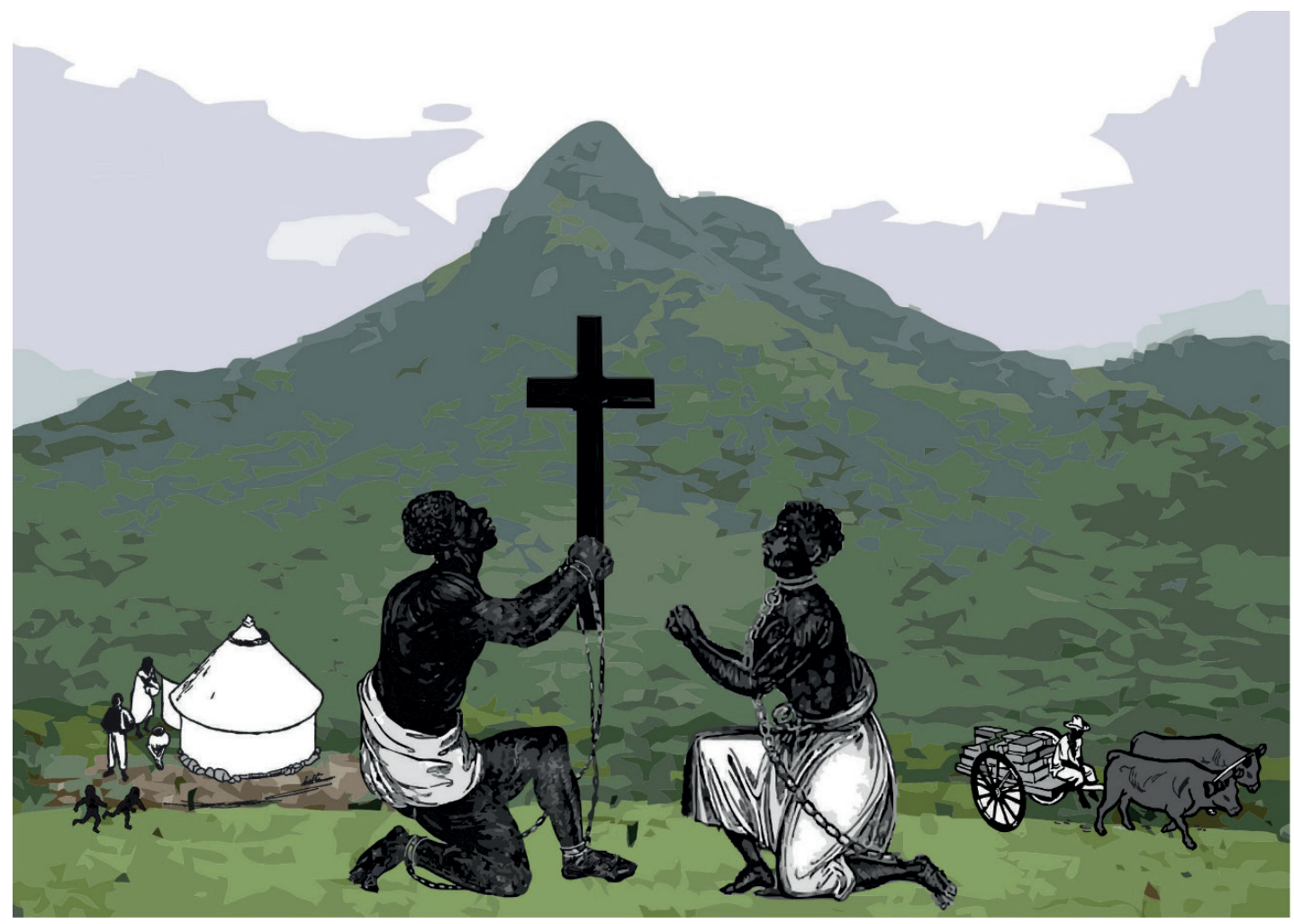

Negros

esclavos labradores de la tierra y ganaderos en Yapatera, siglo XVIII. Redibujado por Pavel Espinoza Ortega, 2019.

orilla del mar Pacífico y el piedemonte andino como Tambogrande, Yapatera, Morropón y Salitral. Este espacio territorial estará conformado por varios tablazos desérticos, pero también por una multitud de zonas planas o de caídas de pequeños ríos que finalmente terminan por desembocar en el río Piura. Por tanto, a lo largo de este río se han formado medianas y grandes haciendas que van a rodear a la ciudad de SM de Piura y que por temporadas climáticas van a tener una fuerte presencia de familias de esclavos y libertos no solo para actividades productivas sino también para el transporte del algodón, la cascarilla, los cordobanes y las suelas, las lonas y las velas, y la crianza y reproducción de lotes de ganado caprino y vacuno que serán vendidos en el puerto de Payta.

Ahora bien, el otro valle de asentamiento y de residencia fija y temporal de los negros esclavos y libertos es el valle de La Chira y el pueblo y puerto de Tumbes. La Chira es el nombre de un río y valle que abarca desde Poechos en su parte alta y en el otro extremo, el pueblo de Amotape cerca al mar. Al interior de este espacio geográfico se han organizado varias haciendas y pequeños pueblos rurales en la que se asientan numerosas familias de peones asalariados, colonos campesinos, negros esclavos y familias blancas y mestizas. En este valle sobresale la hacienda Tangarará y Máncora, pero también otras medianas haciendas como Macacará, Pucusulá, La Capilla, Sojo y Poechos por ejemplo. Hacia el norte también se encuentra el pequeńo poblado de Tumbes vecina a Pariñas y rodeada de medianas y pequeñas haciendas ganaderas y de pequeños grupos de comerciantes criollos que se dedican al comercio y al contrabando de toda clase de mercancías. ${ }^{1}$

Esta provincia compuesta por cuatro micro-espacios (SM de Piura, Morropón-Yapatera, TangararáMáncora y Tumbes-Pariñas va a registrar las principales apariciones de resistencia de las familias e individuos africanos frente al sistema colonial borbó-

1 La producción y comercio de la brea fue un tema que trabajó Pablo Macera (1963). Una actividad económica que luego buscaron explotar algunos miembros de la elite limeña como el marques de Salinas en 1826. En la ciudad de Bolívar, 22.08.1826. En casa de Luis José Orbegoso, General y Prefecto del Departamento, se registra que habiéndose formado un expediente para el arriendo de la mina de Brea cita en Amotape por auto del Supremo Gobierno de 29.04.1826. El contrato propuesto es por cinco ańos y se precisa que el producto del arriendo servirá para costear a una escuela en el pueblo de Amotape, atesorándose el resto a un fondo público. Firma. Serra y Bolívar, 19.05.1826. Mina de brea de Cerro Prieto. Francisco Xavier Fernández de Paredes postula por 400 pesos por ańo. Archivo Regional de La Libertad, 1819-1822. Escribano José Ayllón, Protocolo N. ${ }^{\circ} 441$, fs.922-925v. 


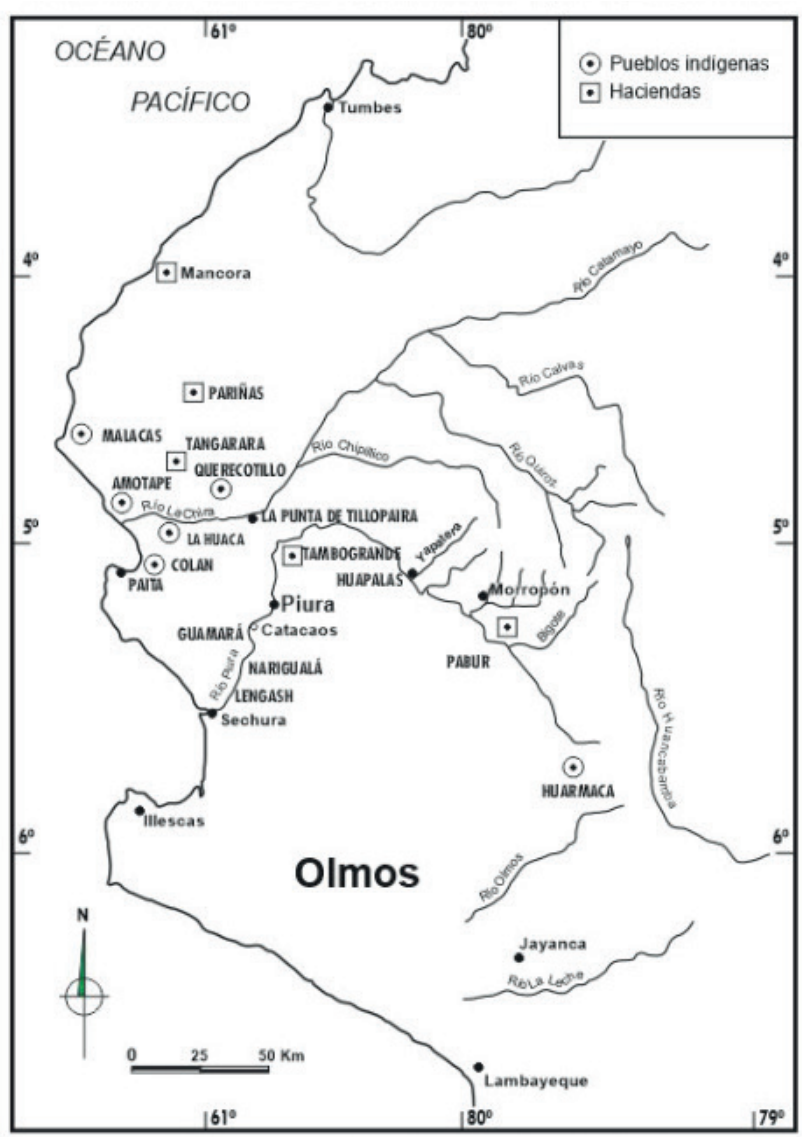

Distribución de pueblos de indios y haciendas en Piura, comienzos del siglo XIX. Fuente: BIFEA, 1991, 20(2), p. 313. Redibujado por Enrique Corpancho León.

nico expresado en la constitución de fugas de cimarrones y la formación de pequeños y grandes núcleos de palenques desde finales del siglo XVIII hasta comienzos del siglo xix. Junto a estos grupos de cimarrones y de palenques funciona también la práctica del bandolerismo rural con la formación de bandas multiétnicas que recorrerán el tablazo desértico de Olmos-Sechura-Catacaos pero también los montes y bosques que rodean a los afluentes de los ríos Piura, la Chira y Tumbes (César Espinoza 2019a).

\section{Palenques y cimarronaje levantados entre los médanos y los bosques de algarrobo como herramientas de resistencia al sistema colonial esclavista}

Susana Aldana escribió un libro sobre las tinas de jabón en Piura concentrando su análisis en el comercio y los comerciantes que viven del trabajo de los negros e indígenas al interior de las estancias ganaderas y las fábricas asentadas a orillas del rio Piura. Se trata de un estudio que aborda la dimensión económica regional que permite conocer las identidades raciales y étnicas de los trabajadores productores de jabones y de cordobanes. Revisando y examinando documentos de archivo estudia a los grandes comerciantes, pero también presenta y describe a la población marginalizada e invisibilizada en la historiografia regional. Se trata de una investigación que busca romper con el mito del mestizaje y de la armonía racial introduciéndose al estudio de la población negra explotada por un grupo pequeño de familias blancas criollas y españolas. Esta autora confirma que los sectores populares compuestos por negros e indios son los constructores de sociedades, pero sin profundizar su actuación en las dinámicas políticas y su marginación en la historiografía regional (Susana Aldana 1988. Jean-Pierre Tardieu 2018 y 2004. Bruno Pinheiro. 2016: 22-36).

En los textos que hemos publicado en estos dos últimos años se ha realizado una descripción y análisis sobre las relaciones socioraciales dentro y fuera de la ciudad de SM de Piura, de igual forma se ha postulado algunas proposiciones de trabajo acerca de la participación popular durante el tiempo de gobierno de los Borbones y la guerra de la Independencia y la formación de la República y los alcances logrados durante las campañas de abolición de la esclavitud y las consecuencias políticas para comprender el proceso y las dinámicas de las relaciones raciales para comienzos del siglo XIX (César Espinoza 2019a; 2017; 2016; 2016a, 2016b).

La falta de estudios y de monografías locales ha hecho dificultoso describir la sociedad piurana a finales de la Colonia con la presencia dinámica de la población afrodescendiente. Los registros de Aduana y de Real Hacienda nos permitieron confirmar la gran heterogeneidad de los individuos afrodescendientes que en el siglo XIX terminaron por concentrarse en lo que después se llamó «Barrios arriba» y finalmente a mediados del siglo xx el barrio de la Mangachería.

En la ciudad de SM de Piura coexisten varias poblaciones de diferente procedencia étnica; en el «Barrio de Abajo» o San Teodoro están las familias cañaris que se instalaron después de 1588 y a la que se sumaron las familias de Catacaos, de Sechura y Colán; al interior de los barrios de la ciudad se encuentran familias de negros/as esclavos y libertos de distinto 
tamaño y al otro lado del río, se va formando un núcleo de familias indígenas y mestizas que suministran mano de obra para la hacienda y tina de Miraflores, llamada El Tacalá y posteriormente Castilla.

San Miguel de Piura está rodeada por una diversidad de núcleos poblacionales dispersos procedentes de las parcialidades de Catacaos por el Sur y los colonos y labradores campesinos asentados en las haciendas de Terela, Chapallirá y Tambogrande. Este pequeño núcleo urbano va a estar rodeado por las tierras de "Los Ejidos" y vastos territorios con bosques de algarrobo y hualtaco con poblaciones dispersas conductoras de rebaños de ganado cabrío que administra la Iglesia de San Francisco y La Merced y amplios territorios con poblaciones multiétnicas dispersas, familias de sirvientes y colonos, también por palenques con esclavos fugados, chicheríos y potreros que sirven de fronteras de propiedades ganaderas pequeñas y medianas. En su conjunto estamos frente a una variedad de asentamientos humanos con estructuras sociales movibles y en muchos casos temporales según el comportamiento del calendario y los ciclos de las alteraciones climáticas (César Espinoza 1999 y 1985).

La vida social en el campo es muy peligrosa, junto a los árboles viven otros animales que los campesinos buscan domesticar; el mundo social dentro y fuera de la hacienda todavía está atravesada por actividades agrícolas en pequeña escala pues la gran mayoría de la gente está ocupada en la crianza de toda clase y tamańo de ganado para la reproducción y el engorde. En este tipo de economía rural también se ocupan las mujeres usando el machete y el hacha para trabajar con la leña del algarrobo, usando las manos para recoger el maíz y la yuca, para preparar los fogones y hervir el maíz mote junto al trigo serrano. Entre la población afrodescendiente está vigente la ideología de la maternidad que le ha impuesto el amo y la dueña de la casa. La procreación es violenta e impuesta para que las criaturas luego sean vendidas o utilizadas como mano de obra para expandir las tierras de hacienda o multiplicar las cabezas de ganado que usaran los tineros para extraer el sebo, la grasa y los cueros para la producción de los jabones y los cordobanes. Las mujeres negras van a servir para la procreación anual y para las tareas domésticas, por esto es que avanza una legislación que las protege y les otorga una falsa protección e ilusión de libertad con la ma- numisión de gracia o con la entrega de cantidades de moneda en plata para transitar al mundo de las libertas y casarse con un negro esclavo o mulato esclavo. Los afrodescendientes viven en un mundo de muchas prohibiciones y en un mundo violento que los busca corregir con la intervención de las autoridades o el uso del látigo y el cepo en la real cárcel de la ciudad de Piura.

Con la organización de los barrios también se registra la multiplicación de los oficios artesanales y de las cofradías locales. Para las familias blancas y la conservación simbólica de su jerarquía social era necesaria la posesión de mujeres y varones negros que ocultaban y silenciaban el sistema de la reproducción forzada y ocultaban las largas jornadas que desplegaban en el trabajo doméstico, el transporte del agua, los sistemas de guardianía y el manejo de los coches y calesas en la que se transportaba el dueño y la familia en su vida cotidiana. En el archivo se encuentran varios expedientes en la que se registran una forma velada de resistencia social de las mujeres negras por la no cancelación de sus salarios o demoras en la entrega de los pagos bajo la forma de bienes agrícolas o pecuarios.

Casi nada sabemos sobre la crisis personal y mental de llevar sobre su cuerpo tumores cancerosos o ciclos de neurosis que provocaba las prolongadas jornadas laborales o el traslado intempestivo de la familia hacia los espacios cordilleranos como Huancabamba o Huarmaca. El consumo del tabaco y de los cigarros fue intensivo provocando la muerte temprana de hombres y mujeres; los protomédicos muchas veces recomendaban una terapia que terminaba con breves internamientos en el Hospital de Belén y la extensión del certificado de defunción por los capellanes encargados. La viruela y la sífilis estaba presente y se intensificó a finales del siglo XVIII conforme avanzaba la mercantilización y la formación de los negocios ganaderos y algodoneros.

La colonización borbónica fue brutal porque llegó incluso a borrar las toponimias de origen de las familias afrodescendientes. La Iglesia católica les impuso nombres de santos y santas religiosas y era obligatorio el bautizo, el matrimonio y la defunción asistida por un clérigo o cura local.

Un sector de los negros varones acompaña a sus amos en sus largos viajes hacia la ciudad de Trujillo y Lima. Son gente que ha aprendido a leer y a escribir 
y gozan de la confianza íntima de los amos y amas para transportar cantidades de plata en moneda de ocho reales y el oro bajo la forma de joyas de diverso tamańo y valores en castellanos. Muchos gozan de la categoría de libertos y son poseedores de mujeres y solares que viven en las calles circunvecinas a la de sus amos. Estos para asegurar su confianza le otorgan pequeñas posesiones de tierras y espacios para sus huertos y potreros para la crianza de ganado porcino, mular y caprino. A partir de este tipo de interacciones sociales también se dedican a pequeños negocios y a la acumulación de pequeñas fortunas en ganado y en moneda plata.

En los expedientes judiciales revisados muchos amos se enfrentan a las mujeres negras que apoyados por abogados y notarios buscan que las autoridades le concedan sus propios espacios para vivir y reducir el hostigamiento sexual y los maltratos físicos. En los testimonios recogidos se puede verificar la visión racista y degradante que le ha impuesto el sistema virreinal a la población africana. Las mujeres luchan por su vida y contra la muerte, pues en general esta población va a ser presentada como salvaje, ajena a la civilización borbónica. Muchos varones y mujeres terminan sus vidas al interior de las tinas de jabones buscando controlar sus vidas y acciones de resistencia social.

Este tipo de acciones se vuelve mucho más creciente cuando empieza una campaña de traslado de familias negras, esclavas y libertas, hacia los pueblos y haciendas ubicadas en la sierra de Huancabamba, Ayabaca y Huarmaca. Acomodarse a vivir en las lomas de las cordilleras no fue muy fácil, tampoco a vivir en espacios casi vacíos y sin las relaciones de sociabilidad que habían desarrollado en la ciudad, pueblo o hacienda de la costa o zona yunga. Se trata entonces de experimentar una forma nueva de vida social que provocará muchas muertes y fugar hacia lugares a veces desconocidos. En verdad, se trata entonces de sociedades en movimiento y a la que desafiando el tiempo y los ciclos climáticos muchos se asentaran reproduciendo sus propios patrones culturales y festivos como lo atestigua Miguel Justino Ramírez (1966) y Juan Paz Velásquez (2013 y 2014).

En suma, este tipo de experiencia social implicará un largo proceso de adecuación a la vida rodeado de la caña de azúcar y el trigo, a la crianza de toda clase de ganado y a otra dinámica de trabajo con otras pobla- ciones vecinas como Jaén de Bracamoros y las montas de Loja (Susana Aldana 1999; Miguel Jaramillo 1998: 51-90). Se confirma entonces la tesis de que en este tiempo tardocolonial existió una sociedad que se está moviendo, como una especie de magma, y que se dinamiza desde abajo, sumando toda una experiencia de vida en la que las mujeres son las que cumplen un papel importante pues reproducen la lógica impuesta de la procreación familiar y de la formación de linajes endogámicos. Es un tiempo en la que las mujeres negras no tienen el control de sus cuerpos ni de sus destinos. La mujer negra entonces está incluida en una organización mercantil del trabajo, con los borbones se ha convertido en sujetos atados a una forma de explotación del trabajo esclavo.

Ahora bien, la organización del sistema esclavista colonial empezó a resquebrajarse a finales del siglo XviıI con las diversas formas de resistencia social, individual y colectiva, de los negros esclavos y libertos criollos. Los negros esclavos prófugos vivirán dentro $\mathrm{y}$ fuera de las grandes propiedades rurales en calidad de cimarrones asentados en pequeños y dispersos asentamientos a orillas de los ríos Piura y La Chira que la legislación indiana las calificó de palenques.

Las otras modalidades de la resistencia social de los negros esclavos en Piura son los palenques ubicados en el piedemonte andino, y el cimarronaje y el bandolerismo rural que azotaba la región de Piura cuyo espacio territorial provincial a finales del siglo XviII se expandía desde Tumbes hasta las pampas desérticas de Olmos

Durante las estaciones climáticas los esclavos negros se fugaban de sus amos, buscaban romper la tutela de sus dueńos o patrones, generalmente grandes propietarios de tierras y comerciantes criollos y españoles. Este tipo de práctica social es categorizada por los jueces con el nombre de cimarronaje. Las autoridades judiciales los calificaron como señales o expresiones de resistencia social frente al sistema virreinal colonial. En el valle de La Chira es casi usual que las aguas que discurrían desde La Punta de Tillopaira (Sullana) se desbordaran más abajo, en las tierras de La Capilla, Sojo, Macacará y Tangarará. De igual formas, las aguas que se acumulaban en el tablazo de Payta colindantes con estas haciendas también terminaban formando grandes lagunas que luego explotaban formándose profundas quebradas o "gargantas» modificando las fronteras de las tierras de hacienda 
y de las parcelas y huertas levantadas por los colonos indígenas, afrodescendientes y familias mestizas que se asentaban temporalmente en ambas orillas del rio.

La explosión y actos destructivos de las lluvias y las lagunas desérticas provocaron que los negros, mulatos o sambos que conducían pequeñas posesiones de tierras de cultivo o la guardianía de secciones de algodón de las haciendas provocaran una inusual dispersión, mudanza o fugas de estos microespacios agrarios para salvarse de la presencia de toda clase de insectos o animales menores que empezaron a deambular por estos campos que en muchas ocasiones provocaban la expansión de epidemias desconocida para las autoridades locales.

En respuesta a la presencia del FEN o a prologados ciclos de años secos se registró una práctica social o escape temporal, que puede ser individual o colectivo, en la que participaban una o varias familias pues los dueños de las tierras habían buscado refugio en la ciudad de SM de Piura. Con esta acción los comprometidos buscarían regular, mejorar o cambiar el contrato que articulaban la vida social entre amos señoriales y negros esclavos.

El negro esclavo que vivía en este valle buscará escapar y trasladarse a otros centros poblados en formación como La Huaca, Tumbes, La Punta de Tillopaira y la ciudad de SM de Piura. La caída de las lluvias torrenciales acompañado de tormentas eléctricas provoca que la gente se mude montado en sus mulas y caballos, portando sus herramientas, y generalmente acompañado de amistades, compadres o colonos campesinos y pequeńos y medianos propietarios rurales para luego de una calma en la caída de las aguas del cielo y las avenidas del rio retornar y reocupar las parcelas y las secciones cultivadas que no han sido dañadas.

Durante estos ciclos de alteraciones climáticas la gente vivirá un tiempo de escape o abandono temporal, colectivo o individual, de terrenos y bosques destruidos por la fuerza del calor o la caída masiva de agua. Son tiempos de vida que les servirán para restablecer los antiguos contratos con sus amos y luchar para cambiar el trato que recibían los esclavos por parte de sus amos, civiles o religiosos. No era raro también que las inundaciones fueran utilizadas para escapar permanentemente de la esclavitud y refugiarse en otras ciudades o valles alejados.

SM de Piura va a ser retratado por Martínez Compañón en 1784 y también por Joaquín de
Helguero en 1802. Ambos son españoles y mandaron dibujar los planos y las gentes que trabajaban encerrados en la hacienda o las tinas de jabones. Piura será retratado como una sociedad costeña multiétnica con sus viviendas y solares, iglesias y capillas con sus torres y campanas a finales del siglo XviII. Fuera de las ciudades, de SM de Piura y otra como Payta a orillas del mar del Pacifico Sur, una densa población indígena la va a rodear desde el sur-oeste y en el extremo opuesto se asentarán las gentes negras o de colores mestizos sin convertirse todavía en miembros de una sociedad civil con derechos y acceso a la educación pública. Cuando caen las lluvias y se estaciona el FEN en toda la provincia se vivirá un tiempo de total desorden económico y social. En los tablazos y los montes como Yapatera, Pelingará o Morropon se reubicarán dispersos una variedad de cimarrones palenqueros e indios rebeldes en los espacios marginales de las grandes propiedades rurales. De tal forma que junto al subdelegado y otras autoridades como alcaldes, regidores y procuradores, y los doctrineros se impondrá un nuevo orden socioterritorial y una práctica cotidiana de la religión y sus misas y festividades.

La ciudad de blancos, negros, indígenas y mestizos estará dominada por un conjunto de haciendas ganaderas que la rodean como Miraflores, Chapallirá y Terela y Tambogrande. Otra frontera que está presente es el cauce del rio y el tablazo de Payta. Las familias indígenas de Catacaos se asientan en las orillas del rio para explotar las parcelas húmedas y la formación de potreros para el engorde y la matanza del ganado vacuno y caprino.

En la provincia de Piura se han organizado una variedad de circuitos mercantiles que la unen a las ciudades serranas de Loja y Cuenca, pero también dependerá de los usos que le dan a los caminos reales, los tambos y los puentes. En esta provincia se ha construido también la economía del contrabando, la corrupción de los funcionarios y una cultura de la ilegalidad con la renta del tabaco y de la cascarilla. Un sector de los comerciantes de Piura mantiene sus propiedades en la bahía de Payta, un puerto que les posibilita el contacto con la gente del mundo que se estaciona usando las chalanas, los bergantines y buques para traer el agua desde San Lucas de Colan y transportar el pescado seco y las cargas de mangos y limones que se producen en las chacras asentadas en 
los márgenes de los ríos costeños a los centros poblados emergentes en ambas orillas del rio de La Chira.

El gobierno y la sociedad de Piura vigilará el movimiento de la gente de color, pero también de los viajeros que llegaban usando toda clase de embarcaciones desde Guayaquil-Panamá por el norte. Por el sur, dispondrá de ciudades-mercado para sus producciones como Lambayeque, Trujillo y la villa de Huaura-Chancay.

Durante el siglo XviII se fortalecerá un tipo de manejo de la tierra por hacendados y comunidades indígenas e instalándose en el valle de La Chira una variedad de instituciones y la difusión de las ordenanzas y de los decretos de Cádiz que van a reducir las tensiones sociales y pequeños conatos y rebeliones indígenas.

Los negros y los pardos están demográficamente organizados en una variedad de instituciones que dispondrán de sus gremios de artesanos buscando reforzar las identidades y renovar los calendarios festivos civiles y religiosos.

Esta dinámica de sublevación y fuga de los negros esclavizados, ya denominada y establecida como cimarronaje, permitió la consolidación y reconocimiento de una nueva forma de organización social en la colonia: los palenques. ${ }^{2}$

En Piura no se ha estudiado a este tipo de formación poblacional de los negros esclavos asentados al interior de las haciendas. La información sobre este tipo de población y su dispersión al interior de las grandes haciendas rurales la proporciona el obispo Martínez de Compañón con su visita realizada en 1784 (José Navarro 1990). La información de este año en el Archivo Regional de Piura es casi inexistente y prácticamente ha desaparecido. La sección de protocolos notariales muestra un gran vacío. No se sabe si fue por el impacto y la consecuencia del FEN de 1791 que arrasó con la ciudad o fue gradualmente borrada interesadamente del archivo. Esta situación es muy curiosa ya que los registros notariales debían mostrar los acuerdos escritos asumidos por los dueños de las tierras y la intervención de las autoridades civiles y religiosas para lograr la reconcentración de la población en los núcleos poblacionales gestionados por Martínez Compañón. El comisionado que

2 El tema de los palenques ha sido retomado por Bernard Lavallé 2018: 17-82. También puede consultarse los trabajos de Wilfredo Kapsoli 2014. Herbert Klein 2016; Carlos Aguirre 1990 y 1993. lo representó vigiló el levantamiento de capillas y el proceso de la centralización de la población existente alrededor de estos terrenos cedidos por los hacendados para evangelizarlos y vigilarlos para garantizar un mayor control social y reducir los graves conflictos sociales que se estaban produciendo al interior de las estancias y haciendas rurales. Al terminar el siglo XVIII se reinició un nuevo ciclo de violencia social dentro y fuera de las haciendas porque los propietarios buscaban expandir sus fronteras y reconcentrar la mano de obra indígena y africana que ya laboraba en estos territorios yungas bajo la categoría laboral de peones, sirvientes, colonos, labradores campesinos y pequeńos propietarios de tierras.

Lo interesante de esta campańa religiosa que impondrá el programa de Martínez de Compañon es que se transita de la vida social en los palenques a la formación de centros poblados rurales al interior de las grandes propiedades agrícolas y estancieras. Surgieron entonces nuevos centros poblados multiétnicos que luego se transformaron más adelante en el siglo XIX en unidades distritales como Tambogrande, Morropon, Yapatera, Tambogrande y Querecotillo.

Los grupos de criollos, indígenas y de negros esclavos acudieron al poder judicial y al parlamento en Lima para solicitar y exigir que se les otorgue la categoría de distrito para gozar de la protección del Estado no solo desde el presupuesto sino también con las leyes a los líderes y ciudadanos locales. La población subalterna y marginada utilizará las reformas políticas borbónicas y a los religiosos para lograr ganar el acceso a la tierra, a la posesión de tierras de hacienda para construir nuevas bases urbanas y acceso a los derechos civiles para incorporarse más tarde como milicianos urbanos y rurales a la vida política local y nacional (Alejandro Diez. 2000: 91-107. Carlos Gálvez Peña: 581-600).

Los trabajos que he realizado y otros que ya empiezan a circular producidos por la academia universitaria muestran como a finales del siglo XVIII se producirá un mayor crecimiento en el accionar violento de los cimarrones que buscaban reformar el sistema colonial que los apresaba y oprimía sin llegar a construir organizaciones o un programa político. La gente negra esclava fuga de la ciudad o de la hacienda y se refugia en los montes y las quebradas para sobrevivir en sus reductos territoriales para gozar de una relativa libertad explotando las orillas de los afluentes de los 
ríos o los puquiales existentes rodeados de bosques de algarrobo logrando acumular y disponer de un pequeño capital ganadero y de conocimientos sobre los cambios que estaban ocurriendo en la política virreinal (César Espinoza 2019 y 2019a).

Podemos entonces postular la proposición de que el cimarronaje y los palenques son mecanismos usados por la población negra esclavizada para asumir la forma de expresiones de sublevación ante una formación socioeconómica virreinal que los encerraba al interior de las fábricas y talleres de producción del jabón y los cordobanes, pero también al interior de las fronteras de las grandes estancias ganaderas.

Usando el sistema del cimarronaje los individuos o familias lograron disponer de pequeños lotes de tierras, de un capital ganadero y de pequeñas sumas de moneda y barras de plata para mejorar sus condiciones de vida. Hombres y mujeres practicaron la fuga permanente o temporal para provocar que los dueños les mejoraran las condiciones de vida ofreciéndoles una casa donde vivir o mejores salarios y muchas veces el cambio de amo y ama.

Para los espacios geográficos de Tangarará, Yapatera y Morropón, los palenques asumieron varias modalidades. Los cimarrones no necesariamente vivían aislados y por el contrario buscaron estar conectados con los caminos usados por los arrieros que recorrían la costa y la sierra andina. Por el tamaño espacial de las haciendas, estos palenques finalmente asumieron la forma de microespacios autónomos de vida social, económica y productiva buscando vivir alejados de las autoridades municipales, del Estado virreinal y de los dueños de las tierras.

Un negro esclavo podría transitar su vida desde un taller de jabones-cordobanes a gozar de un pequeńo lote de tierra de humedad y vivir con una mujer $\mathrm{u}$ otros negros esclavos fugados a los cuales se podrían sumar mestizos pobres y criollos blancos. Esa comunidad autónoma y micro-asentamiento de cimarrones van a reproducir un sistema de vida social libre de los castigos y las discriminaciones y duras jornadas de trabajo sobre explotador.

Es al interior de estos microespacios rurales llamados palenques que van a desplegarse una variedad de estrategias de resistencia realizadas por individuos, familias o la comunidad de gentes ya sea cultivando pequeños lotes de tierra o vivir del asalto a los arrieros y viajeros que subían o bajaban de la sierra. Se trata de grupos de gentes de diferentes castas que finalmente se agrupan para sobrevivir y que organizan espacios alternativos al sistema de haciendas y de la ciudad de SM de Piura. ${ }^{3}$

A finales del siglo Xviı se organiza por los afrodescendientes al interior de estos microespacios un conjunto de espacios sociales alternativos a los que buscaban imponer los subdelegados y los religiosos de las ordenes de San Francisco y La Merced para disponer de una masa de brazos para proseguir con los negocios de los cueros y jabones, y con el algodón y la cascarilla. La historia de cada uno de estos palenques es singular porque en el valle de La Chira ocuparan generalmente un espacio territorial bańado por un río durante todo el año. Todo lo contrario, ocurrirá con los valles afluentes cuyas aguas desembocan en el rio Piura. En este valle el cauce del rio solo gozará del agua durante tres o cuatro meses del año. Los meses restantes son de la carencia del agua movilizándose el peonaje y los colonos campesinos hacia las tierras de hacienda con suelos húmedos o de puquiales y con densos bosques de algarrobo.

La vida social campesina se complica mucho más cuando los ciclos de alteraciones de años de lluvia o de sequías registraron un tiempo prolongado de años secos que en algunas ocasiones llegan a una docena para luego explotar los valles con la llegada de lluvias y huaicos y el despliegue de tormentas eléctricas marcados por un FEN muy fuerte. La vida en la ciudad, al interior de las haciendas y de los pueblos y de los palenques quedará impactada por la fuerza de la naturaleza pues las lluvias y los huaycos que provoca la abundante concentración de la masa de agua que circula por los cauces de los ríos inundaran las pampas de Pabur, de Malingas, Sol Sol y Tambograndes formándose grandes lagunas y dispersando a la gente de los palenques que sobrevivían al interior de estos espacios de autonomía territorial, social y económica formados en la región de Piura.

En efecto, paralelo a la actividad del tráfico de negros esclavos en la ciudad de SM de Piura y el puerto de Payta se registra a finales del siglo XviII el fenómeno de la resistencia de las poblaciones negras esclavizadas asentadas dentro y fuera de las haciendas y los centros

3 La constitución del cimarronaje y de los palenques en los montes de algarrobo y zapote cuyos actores transitan al interior y en los alrededores de la ciudad y la gran propiedad terrateniente puede examinarse en César Espinoza Claudio 2019: 195-222. 
poblados. El cimarronaje se volverá intenso en la costa y la sierra de Piura, una región en la que se había levantado un sistema de haciendas y de estancias ganaderas ocupando tierras y concentrando mano de obra negra esclava y de otras castas en los valles de Tumbes, La Chira y el Piura. Esta acción social del cimarronismo fue una práctica social condenada y perseguida por los corregidores y subdelegados apoyados por los propietarios de las grandes haciendas y un pequeño núcleo de comerciantes dependientes del Consulado de Lima que intentaron instaurar la paz social para asegurar el flujo comercial de una región económica bisagra con los pueblos andinos de Loja-Cuenca por el norte y Lambayeque-Trujillo por el sur. Los negocios de los jabones-cordobanes, del algodón-cascarilla y de las mercancías europeas procedentes de la ciudad de Lima obligaron a intensificar una campaña persecutoria y de liquidación de los palenques asentados en el piedemonte andino de Yapatera-Morropón y de Tangarará en el valle de La Chira.

Durante este tiempo no solo se había expandido el cimarronaje sino también la formación de una variedad de micropoblaciones que empezaron a ocupar temporalmente las tierras y fronteras de grandes haciendas para laborar como peones y colonos campesinos para luego transitar a otro momento de residencia fija ante la inclemencia y el ataque de los ciclos climáticos, en particular, de los ciclos prolongados de sequía que obligaron a estas poblaciones campesinas negras e indígenas a ocupar tierras y microespacios de «humedad», ya sea a orillas de los ríos y sus afluentes o de los ojos de agua que se dispersaban entre los tablazos desérticos y quebradas de las haciendas y estancias ganaderas y también al interior de las tierras comunales como las de SJB de Catacaos, Sechura, Olmos y San Lucas de Colán. Estos microespacios territoriales arrebatados al control del dueño de las tierras son los palenques que serán usados no solo por los negros esclavos que fugaban de la ciudad y de las haciendas sino también por los negros libertos, los mestizos, los indígenas e incluso blancos que abandonaban las milicias organizadas por los Borbones como es el caso de los batallones de Dragones de Amotape.

En un tiempo muy corto esta población de esclavos prófugos se convertirá en un gran problema social y político para el Estado virreinal y la elite de criollos y españoles que los presentaran ante el virrey y los alcaldes, pero también ante el público y los jueces y abogados de San Marcos para empezar a ser calificados con la categoría de bandoleros, delincuentes y toda clase de subjetivaciones con la finalidad de reprimirlos e imponerles marcos legales y milicianos para conseguir el orden social virreinal.

\section{La vida social de los negros esclavos y libertos frente a los ciclos de sequías y lluvias, incendios y esterilidades en las tierras de haciendas ubicadas entre Olmos y Tambogrande, y entre Pabur y la ciudad de San Miguel de Piura: 1780-1822}

Don Mariano Salazar, regidor del Ayuntamiento de Piura y apoderado de las "haciendas de Valles» que pagan la alcabala o derecho de cabezón de años atrasados «después de las absoluciones superiores que obtuvieron ante Usted», (f.1) solicita mediante un escrito que se esclarezca si ha sufrido o experimentado la provincia de Piura una absoluta falta de aguas y los graves daños que de consiguiente se han experimentado a los propietarios de tierras y vecinos que viven fuera de la ciudad de San Miguel de Piura y de otros centros poblacionales rurales para disponer de una posición sobre la cancelación o exoneración de las rentas fiscales.

La investigación sobre el impacto de las alteraciones climáticas en los negocios rurales se realizó por las autoridades de la ciudad de Piura primero en el año de 1806 y procesado el reclamo se corroboró en 1813 con la absolución en la cancelación de las rentas que debía entregarse al Estado virreinal. En esta ocasión, los hacendados registrados en las doctrinas de Ayabaca, parte de la sierra de Piura, son los que llevaran la defensa de este reclamo, y que ahora por tercera vez, estas partes interesadas han sido absueltos, un asunto crucial que para la marcha económica de la región procesa e informa el Gobernador Intendente Don Vicente Gil en 1819, y anotándose que a la fecha ya se acumulaban tres sentencias favorables. Esta autoridad virreinal señalará que todo lo mencionado debía estar registrado en el Tribunal de Cuentas de Lima. Y que ahora con la finalidad de reforzar este nuevo reclamo ante las autoridades de Lima se solicitará la autorización para que se presenten nuevos tes-

4 Archivo Regional de Piura (ARP). 1822. Caja 13, Expediente 224; 98 fs. GPM, Causas Administrativas. Cuaderno 2do. Autos sobre la recaudación del derecho de cabezón de las haciendas de este Partido, Piura. 


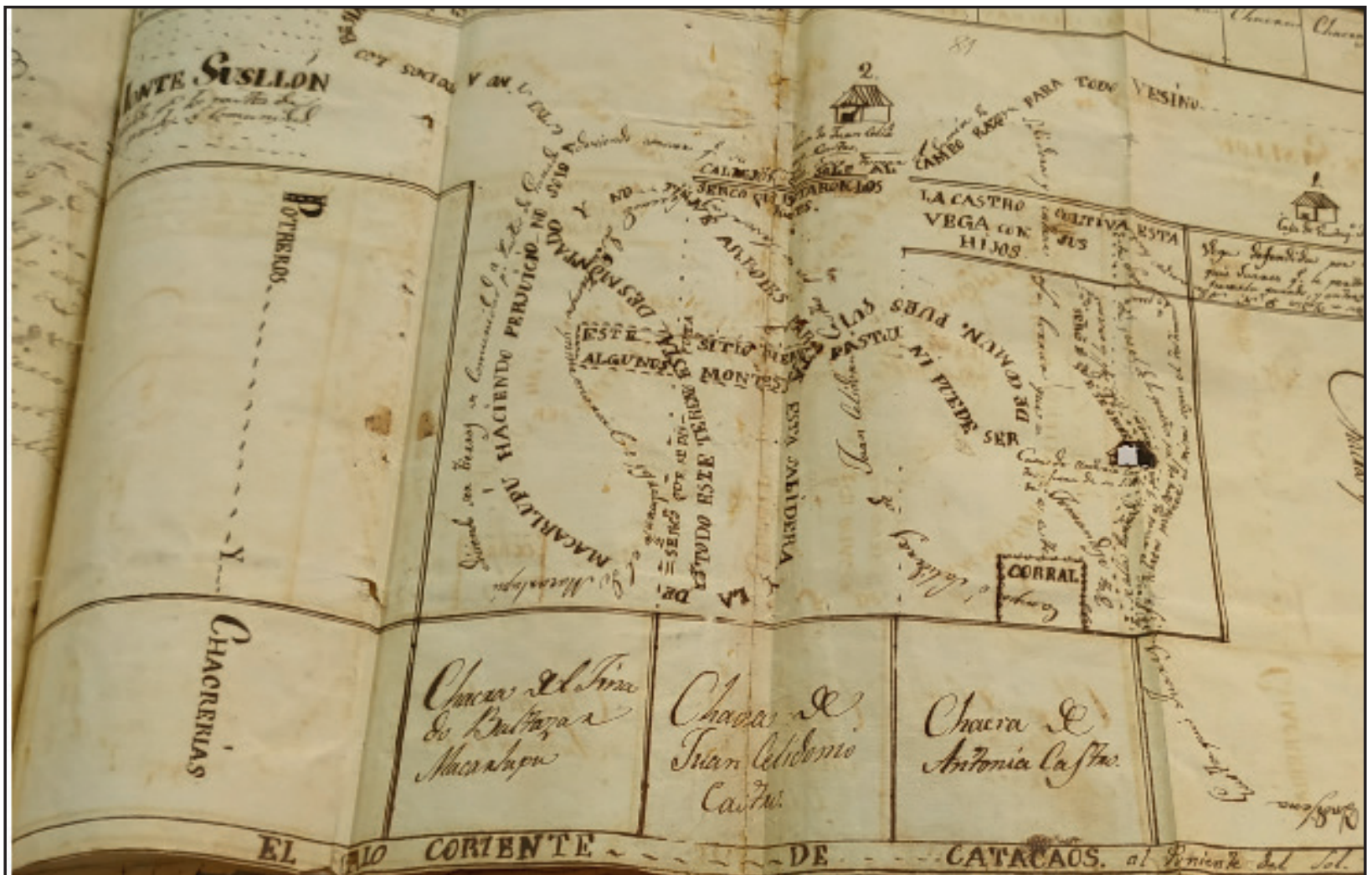

Plano de cauce del rio Piura en el sitio de Monte Sullon y pleito por tierras parcelarias y de la comunidad indígena de San Juan Bautista de Catacaos 1803-1852. Fuente: Archivo Regional de Piura.

tigos para recoger sus declaraciones orales y escritas. De tal forma que para esto se incluye un cuestionario que resumiría los indicadores climáticos y el estado de la vida social regional:

1. Que se vivió una falta de aguas desde el año de 1793-1794 y que recién llegaron las aguas en 1811 y 1819 , "habiendo habido en su intermedio garubas (garúas) perjudiciales para podrir como han podrido los algarrobos» (f.1v).

2. Que con la falta de aguas creció la mortandad de los ganados mayores y menores de las haciendas y entonces quedaron "cubiertos los campos de guesamenta de los dichos ganados por no haber pastos» (f.2).

3. Que «en los años que hubieron aguas, los pastos que se criaron... han sido incendiados" y los pocos ganados que sobrevivieron se han «remontado y levantado", es decir, subieron a los montes y entradas de las cordilleras, buscando desesperados que comer y las haciendas por tanto quedaron con sus cascos limpios y los productores apenas lograron alcanzar lo necesario para pagar sus pensiones y deudas.
4. Que ninguna hacienda es de la categoría de «pan sembrar", y que no producen ninguna cosecha de granos y solo se dedican a la crianza de animales. Los años de crecimiento "pingue» fueron de los años 80s a los 90s del siglo XVIII, un tiempo climático en la que obtuvieron capitales exorbitantes y los campos estuvieron cubiertos por todo tipo de ganado.

5. Que desde el año de 1820 se ha suspendido la llegada de las aguas, y los ríos ya no riegan sus orillas para sembrar por los colonos campesinos de las haciendas y lograr su manutención. Los campos que se conducen no son de riego y lo que se viene es un tiempo de una calamidad irreparable. Precisa que en los tiempos de escasez caen las "garubas» que produce la multiplicación de una yerba llamada la «borrachera» y otras más que cuando la comen los ganados estos mueren casi inmediatamente (f.2).

En 07.05.1822, Don Francisco Escudero, en su calidad de Gobernador Político y Militar de Piura admitirá esta petición de información presentada y encargó que participe el responsable de la oficina de 
la Receptoría Don Vicente Navarrete para así lograr conservar el orden social.

En la ciudad de Piura, en 08.05.1822 declara D. Juan Velásquez, labrador y habitante del paraje de Vicus, edad 49 años. Este señala que vivió desde los siete años en Vicus, sitio de la hacienda de Guapalas protegido por su tía D. María Tabara y sabe y conoce que «hubieron aguas generales en estos valles, de que resultó la abundancia de pastos para la manutención de crías de ganados de las haciendas pero con la desgracia de que se alzaron y no volvió a llover hasta los años de 803 y 804 , y no abundantes, como las de 91, que los pastos que produjeron las aguas de aquellos años fueron incendiados, habiendo empezado el fuego desde las inmediaciones del pueblo de Olmos y llegado hasta Palo Santo distante de esta ciudad como a seis leguas, cuyo fuego no se pudo apagar por más diligencias que hicieron los dueños de las haciendas» (f.3).

Recuerda el testigo Velásquez que en ese tiempo era mayordomo de la hacienda Guapalas y que para apagar el fuego salieron todos los «sirvientes» $\mathrm{y}$ «colonos», y que entonces no pudieron conseguirlo quedando destruidos los campos de pastoreo y potreros de madera.

Lo mismo ocurrió en las otras haciendas; que sin pastos el ganado se cae y muere. La esterilidad que se producirá después del año de 1791 va a ser seguida por unos años secos y la lluvia recién llegará el año de 1811, pero esta vez sin la abundancia conocida. En 1819 caeran nuevamente las lluvias, pero ya no se producirán los incendios señalados, sin embargo, lo singular de este tiempo es que los pastos que crecen solo duran dos años sin aguas y no más, un imprevisto que la naturaleza los sorprende.

Agrega que en los años secos caen las llamadas «garubas» que pudren las algarrobas y se crían y reproducen dos clases de yerbas: la "borrachera» y la "vinagrillo», que ahora abunda en el despoblado y que al comerlas las cabras mueren (f.3).

A la pregunta 3 responde que los ganados se alzan y mueren, que las haciendas solo producen para poder gastarlos en sus pensiones como son los réditos de los principales de los censos y el pago de los sirvientes para finalmente obtener una limitada subsistencia.

Anota que las haciendas de los «valles» no son de "pan sembrar» sino de crías reproducción y crianza de ganado) y que se viven tiempos con pocos años de abundancia de aguas seguidos de ańos con esterilidad.
Precisa que desde el año de 1819 a 1822 no llueve y que solo se ha visto caer unas garuas perjudiciales, y que los pastos emergentes del año de 1819 terminaron quemados y que esta vez el fuego, que empezó en el sitio llamado de «Tortolitas» finalmente se cortó y apagó por los linderos de la hacienda de Ñomala.

Concluye seńalando que la falta de aguas no permitió una creciente y abundancia de este líquido en el rio y que por tanto ya no se riegan sus orillas para que puedan sembrar los colonos campesinos de las haciendas y lograr así ganar su subsistencia. En suma, crecieron los espacios de tierras de orillas que no tienen riego y que lo que viene es un tiempo de mucha escasez de granos y ganado, una situación que también afectará a la gente que vivía en la ciudad de Piura que ahora está atravesada por un río totalmente seco.

Luego prosigue ese mismo día la declaración de D. Manuel Gómez, quien señala que nació en Vicus, y tiene edad 32 años, y que vive en un sitio de la hacienda llamada Guápalas. Recuerda que sus padres fueron trabajadores «vivientes» muchos años trabajando en la tierra del sitio de Vicus. Señala que en el año de 1791 las aguas que cayeron fueron abundantes y que luego transcurrió un tiempo de años secos que duró hasta 1803-1804, fueron dos años de abundantes aguas en la que los campos y potreros gozaron de muchos pastos y con un suelo en la que no podían caminar los labradores y pastores por el despoblado. Después ocurrió el incendio de todos estos pastos desde el pueblo de Olmos y que la gente no pudo apagarlo pese a una gran movilización de los dueños, los mayordomos, los sirvientes negros y los colonos campesinos; y que después volvió a llover en el año de 1819.

Recuerda también que en el año de 1820 no hubo aguas y que esta vez se consumieron los pastos que aparecieron en 1819; después en el año de 1821 si hubo aguas y pastos, pero esta vez nuevamente se producirá otro incendio de los campos y se quemaron los bosques de algarroba que gozaban las haciendas; este fuego empezó por el sitio de "Tongo", en la hacienda de Pabur, más abajo de Tortolitas, y de Guapalas, en el sitio de "Alto Pelado". Su testimonio precisa que en estos lugares se produjeron tres quemas o incendios de los pastizales que servían para engordar toda clase de ganado mayor y menor.

Frente a esta eventualidad recuerda que las autoridades y los propietarios y dueńos salieron a apagarlo 
Piura. Mapa de la hacienda Sol Sol con sus ríos temporales, descripción de caminos, huacas, trapiches y viviendas. Siglo XVIII

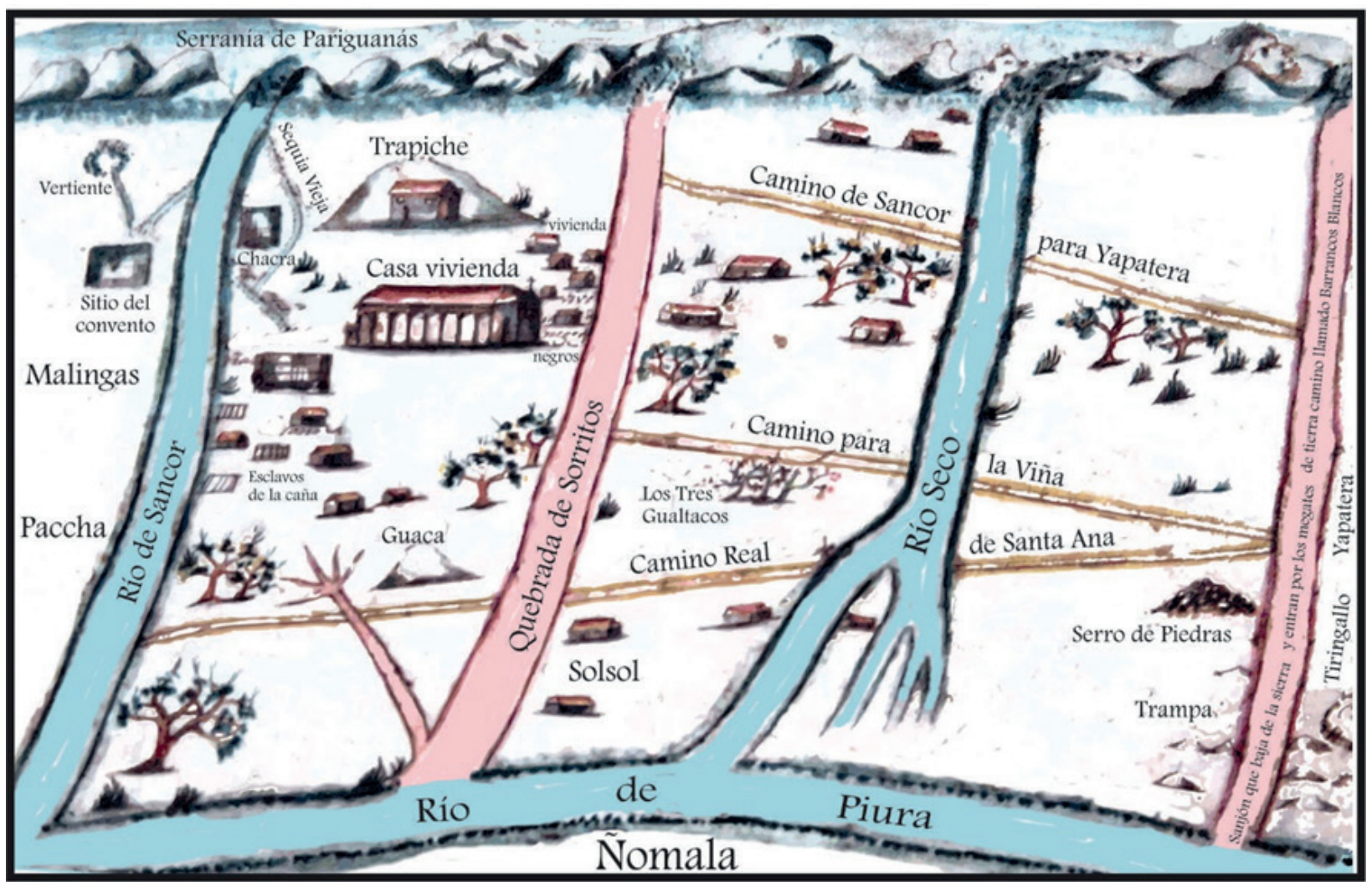

Fuente: Mc Donald Checa, James. Testimonio de hacendado (2014). Asociación Cultural Peruano Británica. Lima, Perú, pág. 50.

Mapa digitalizado, vectorizado y editado por Pavel Espinoza Ortega (febrero 2017).

con mucha gente de Guapalas y de otras haciendas y que esta vez el fuego solo pudo detenerse en los linderos de Guapalas vecino a Tambogrande.

Termina su testimonio señalando que en el año de 1822 no hubo aguas, los ríos esta vez no tienen sus crecientes que servían para regar las orillas en las que siembran los colonos de las haciendas y calcula que en adelante habrá mucha escasez de víveres, y que la algarroba escaseará en los campos y no se podrá mantener a las bestias de servicios (f.5-6).

A continuación, declara D. Manuel Ascencio Navarro, edad 61 años, peruano, natural del pueblo de Catacaos y habitante en la hacienda de Parales. Avisa que no sabe escribir y al final de su declaración se limita a registrar una cruz con la pluma.

En su testimonio oral recuerda que el fuego del incendio se apagó a 6 leguas de distancia de la ciudad de San Miguel de Piura, expandiéndose la tierra árida y produciendo un fuerte impacto sobre la gente del campo ante este suceso inesperado. Otro de los problemas que se presentaron con los años secos fue la muerte masiva del ganado que solo comía yerbas malas, y que ante la escasez de pastos consumían en su desesperación una planta llamada "yuca del monte» que provocó una alta tasa de mortalidad, se trata de una planta que liquidaba en el campo a toda clase de ganado; así lo vio y sucedió con las yeguas en la hacienda de Parales.

Recuerda también que el año de 1791 fue un tiempo de aguas abundantes; en 1803 también cayó mucha agua; en 1811 y 1819 de igual forma acompañado de tormentas eléctricas y mucha bulla. Es en medio de estas alteraciones climáticas que su padre se dedicó a ser criandero de ganado en la hacienda de Parales, allí tuvo una manada de yeguas y ocurrió que con la escasez del agua solo se quedó finalmente con un garañón y un burro hechor en 1794. En adelante, la vida se le hizo muy difícil con la «suspensión de aguas y la falta de pastos", mucho sufrieron los crianderos y los hacendados ante este ataque implacable de la naturaleza. En 
el año de 1821 hubo aguas, pero poco abundantes y con tan mala suerte de que los pastos que emergieron ese año se quemaron. En el año de 1822 de nuevo se vivió un tiempo de escasez de aguas y de mucha desesperación de las gentes por sus vidas y negocios rurales.

A continuación, declara José Domingo Morales, habitante en la hacienda Pabur, edad 44 años. Este informa que vivió en las tierras de Pabur unos 36 años. Sabe que el fuego que se levantó consumió todos los faiques de esta hacienda. Recuerda que ante el fuego y el incendio se movilizaron y lucharon muchas gentes para combatirla durante un mes. Este episodio se produjo después de la llegada de las aguas en los años de 1803-1804. Entre los habitantes de estas tierras se rumorea que si llueve un año luego siguen $10 \mathrm{u} 11$ años de secas y en la que además en los años que siguen se quemaron los pastos y los bosques de algarroba que servía de alimento a la gente y a los animales. Ante esta situación el ganado de las haciendas huyó hacia los montes y allí también se murieron por la falta de pastos, el resultado es que la casa-hacienda y las tierras que la rodean quedaran prácticamente despobladas.

Otra declaración la realiza José Morales. Este señala que nació y creció en Pabur, tiene 43 años. Recuerda que durante su vida ha visto tiempos y años de secas y falta de pastos, es un tiempo y gobierno de la esterilidad para la gente de las estancias y los pueblos campesinos.

Similar declaración la realiza Simón Carmen. Un habitante de la hacienda de Ocoto y en la que afirma que allí vivió ya más de 40 años. Luego se presenta José Domingo Fernandez, peruano, habitante en la hacienda de Chapallirá, cerca de la ciudad de SM de Piura, edad 54 años y no sabe firmar. Recuerda que el año de 1803 fue un tiempo de lluvias y que en el 1804 se produjo un gran incendio y la quema de los bosques y pastos de los faiques y los zapotales. Agregó, que ese año de 1804 se trasladó hacia la ciudad de Lima como arriero de una recua del finado Juan Sapata y que al regresar encontró que ni las mulas tenían que comer en los alrededores de la ciudad de Piura (f.15v).

En 09.05.1822, presentó su testimonio Anacleto García, un teniente retirado del Escuadrón de Cívicos de Querecotillo, edad 60 ańos. Este hace memoria de que el año de 1803 fue de lluvias y de que en el de 1804 se produjo un gran incendio desde Olmos y que avanzo destruyendo los pastos de Somate, Pelingará y Tambogrande. Afirma que trabajó como mayordomo en la hacienda de Somate y recuerda que en esa ocasión la hacienda perdió dos hombres esclavos «uno por haber segado in totum» y el otro «por haberse vuelto loco y haberse arrojado a ver si lo apagaba» (f.18). También sabe que murieron dos hombres colonos, uno de Somate y el otro de Pelingará, como resultado de que ambos se arrojaban al fuego para defender los animales de la hacienda y los suyos. Concluye señalando que en estos tiempos de esterilidad murieron más de mil cabezas de ganado vacuno y de ganado cabrío y que suman más de dos mil pues no había pastos para alimentarlos.

Otro testimonio lo realiza D. Miguel Carrasco, habitante de la hacienda de Somate, edad 47 ańos. Este recuerda que un colono campesino que murió en este incendio se llamaba Felipe Ypanaqué (f.20). Agrega que «en la hacienda de Somate se quemaron como dos leguas de la Vega nombrada Montecillo que, habiendo reparado el desbande de este fuego, tocó la campana, se recogió toda la gente y con ella se dirigió a apagar» (f. 20v).

En este accionar para combatir el incendio participaron los dueños de las haciendas, los colonos y los «agregados» (f.21). La esterilidad fue mortal pues se formaron "mangas» con la cantidad de reses muertas, quedando secas en los jagueyes ante la falta de alimentos. La sequía cortó el trabajo y la empresa de engordar ganados que se traían de otras provincias. Ante la falta de agua los colonos ya no podían cultivar sus parcelas de orillas del rio y por tanto, en la ciudad se agudizaba la escasez y la carestía de los víveres (f.22). La mortandad fue total y aparecieron y se dispersaron muchas yerbas venenosas como «la pajilla chica» que cuando lo consumían los ganados estos amanecían muertos.

Don Francisco Escudero, alcalde de segunda nominación y Gobernador Político y Militar del Partido de Piura elaboró su informe precisando algunos conceptos y acontecimientos en estos tiempos de alteraciones climáticas. A esta autoridad el asunto que le preocupa es la cobranza de la alcabala de cabezón de los hacendados de la sierra y de los valles para disponer de suficientes recursos monetarios y estar al día en los pagos a los militares y civiles encargados del orden local.

Escudero ordena que el administrador de la Aduana Patriótica «obedeciendo el decreto de V.S.M.Y de (18)21" acelere la cobranza de esta renta fiscal. Agrega que está asombrado de ver la confusión, desor- 


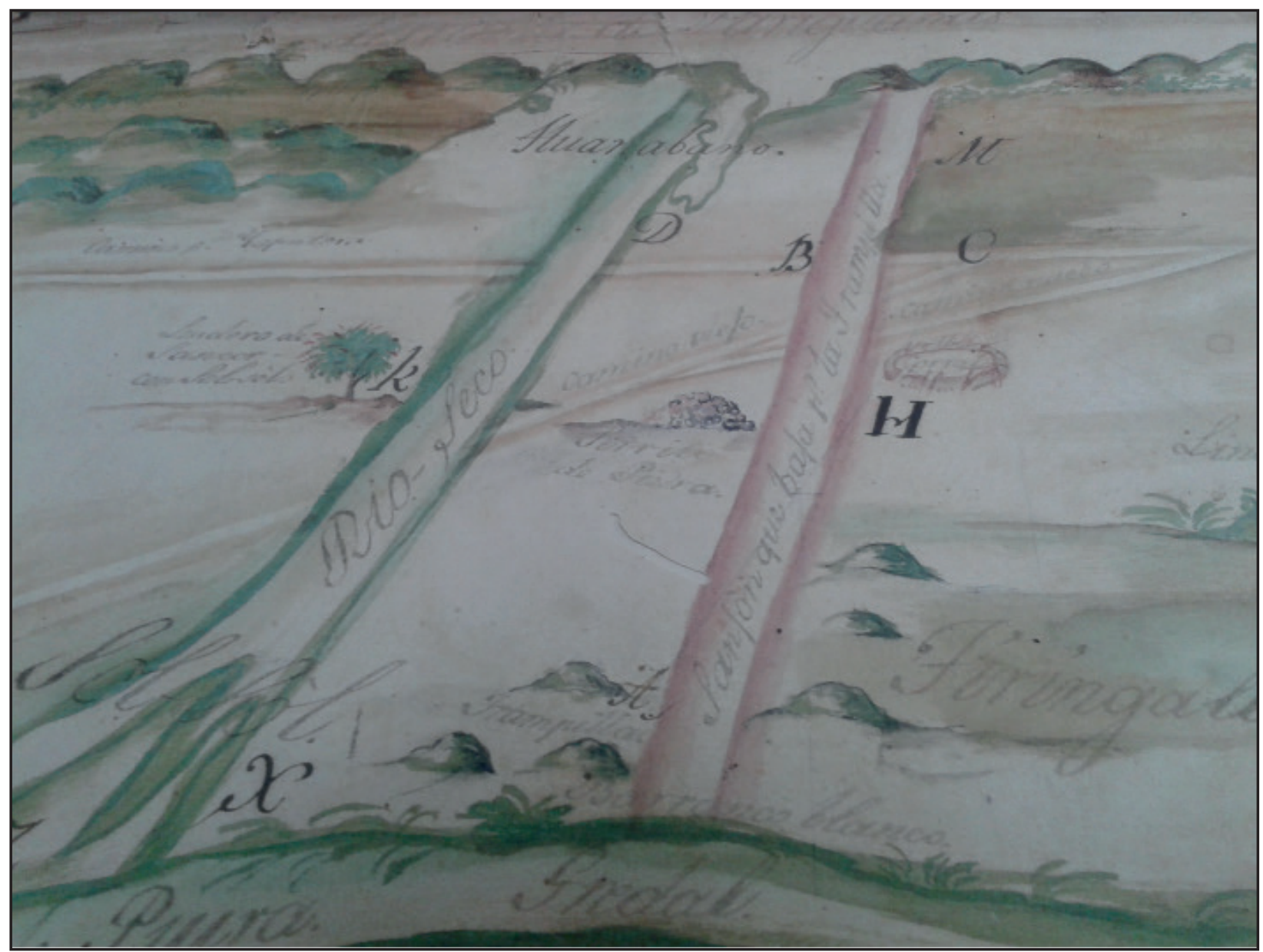

Plano de tierras de Tiringallo, Sol Sol y Yapatera 1823, en la que se registra los cauces y ríos secos por donde circulan las aguas que bajan desde las nacientes cordilleranas. Fuente: Archivo Regional de Piura.

den y falsas aserciones sobre este asunto en el expediente consultado. Entonces empieza apuntando de que «el cabezón es... un derecho de alcabala que adeuda todo predio rustico o urbano, que por ser productivo y tener en sí mismo contratos, debe satisfacer, y siendo imposible el que en estos menudos y reiteradas negociaciones interviniesen las Aduanas, se resolvió que... tomándose juramento a los dueńos de las cantidades que tuviesen empleadas en ese giro interior y rebajándose de ellas una tercera parte quedasen obligados a pagar sobre el resto el 6\% de alcabala» (f.23).

De otra parte, desde la ciudad de Trujillo en 28.09.1821, recibiendo los informes y datos puntuales, el General Arenales ordeno que se remita al Gobernador de Piura un nuevo escrito para que se proceda a la cobranza de lo adeudado en el Ramo de Alcabalas. Firma Arenales y José Serra

En Piura, el 11.12.1821, ya casi para terminar el año, el Gobernador Santa Cruz ordena que se le informe a los hacendados que sufrieron la sequía en los años expresados sobre el pago del cabezón y que se les comunique también sobre este mandato político llegado desde Trujillo a los tenientes gobernadores.

En Piura el 09.03.1822, Escudero tomará nota de la orden de Santa Cruz de 11.12.1821 y encargó a D. Fermín Carrasco, teniente gobernador de Huarmaca, para que en el plazo de 15 días prepare y entregue los informes escritos acerca de los daños sufridos por los hacendados ante la «falta de aguas» (f.24). A continuación, Carrasco comunicará a D. Leandro Echeverre, dueño de la hacienda de Rodeopampa, y también a D. Pascual Tineo, dueño de la hacienda de La Tiza y al Dr. José Dolores Velasco.

En Piura 10.05.18222, se informa que D. Juan José Carrasco se encuentra ausente de la ciudad, este personaje es el dueño de la hacienda de Congoña y Landa, en el distrito de Huarmaca (f.25). Frente a esta eventualidad, el receptor de Rentas D. Vicente 
Navarrete remitirá una carta solicitando que se ubique al hermano de D. Manuel Carrasco, coronel de Infantería para que se le alcance la notificación urgente. Lo mismo lo solicita don Francisco Escudero, el Gobernador de Piura quien exige esta vez que se le entregue el escrito y la orden a D. Juan José Carrasco.

Casi a mitad de ese año, en 01.05.1822, D. Fermín Carrasco, desde el pueblo de «Huarmaca Yndependiente» le avisa de la diligencia realizada sobre la gracia y exoneración concedida a los hacendados y la gestión de suspensión de la contribución de la alcabala del cabezón a los fundos que poseen en la sierra y valles de Piura. Cumplió así con el aviso entregado a D. Juan José Carrasco dueño de la hacienda de Congoña (f. 26).

En otro escrito de D. Manuela Merino, vecina y dueña de la hacienda de San Pablo y Aranza, ubicada en la sierra de Piura, esta informa que ya tiene conocimiento del decreto con fecha 02.10.1821 y también de otro decreto enviado por Francisco Escudero sobre las haciendas y la exoneración del pago del derecho de cabezón de los años atrasados. Merino recuerda que hace 18 años que falleció su esposo D. Miguel Carrasco y le parece que no están al día con la cancelación de esta renta. A todo lo cual se suma el hecho de que los pastos de la hacienda se quemaron en el año de 1807.

En otra parte contenida en este expediente se registran nuevas declaraciones que buscan afinar los contenidos sobre las alteraciones climáticas y los pagos por los hacendados de las nuevas rentas fiscales que está imponiendo el aparato del Estado nacional en construcción. En 10.05.1822, presenta su declaración oral Pedro Regalado Sangines, un hombre que trabaja de mayordomo en la hacienda de San Pablo y también en Cachiaco, unas haciendas rurales contiguas por 14 años. Recuerda que para cultivar en la hacienda de San Pablo se valían de los "peruanos» (indígenas) pero el resultado logrado ha sido que estos solo vivan amenazados y con muchos daños, robos de ganado y la quema de los pastos, tumbando las vaquerías levantadas. De tal forma que podría decirse que a un año bueno le siguió otro año malo. Señala esta vez que esta propiedad rural ubicado en el piedemonte andino requiere de abundante agua para producir los pastos y también otros frutos locales (f.29-29v).

Prosigue la declaración de Narcisco Pozo, Cabo primero de la Segunda Compañía del Batallón Cívico de la Infantería de Piura, edad 30 años. Este testigo informa que trabajó en la hacienda de San Pablo por nueve meses, y que su oficio es la de carpintero, y que esta experiencia la vivió en el año de 1814. Recuerda también que en ese tiempo se arruinaron las vaquerías y murió casi todo el ganado vacuno ya que a la falta de aguas se carecía de la gente necesaria para cuidarlos (f.30). De igual forma también observó que se produjeron graves daños en los aparatos de la molienda y los trapiches (f.30v). Fue ese ańo de 1814 que vio cómo se desparramó un gran incendio en estas propiedades rurales y se acusaron a los «peruanos» de haberlo provocado. Fue un momento en la que se perdieron muchas semillas de trigo, maíz y alverjas. Recuerda de igual forma, que estos granos no se cultivaron en la hacienda de Cachiaco porque allí sus tierras son muy duras (f.30v).

Similar información se encuentra en las declaraciones otorgadas por Floro Mesones, edad 59 años, un hombre criado en la hacienda de Cachiaco y que trabajó en calidad de mayordomo. D. Ygnacio de Ascárate, edad 60 años, precisó que en estas haciendas vivían muchos "peruanos», y que se trata de gentes que trabajan al interior de estas propiedades bajo la categoría de "yanaconas" pero que en el año de 1822 se encuentran casi todos ausentes.

Prosigue la declaración de D. José Garrido, capitán de la Segunda Compañía de Cívicos en Piura. Este afirma que es el albacea de su padre D. Sebastián Garrido, quien le dejo como herencia dos haciendas nombradas Culqui y Pillo, en el territorio de Frías (f.34). Agrega que estas haciendas no cumplieron con pagar la alcabala desde el año de 1797 . Y que el motivo fue que se prosiguió un expediente judicial y el resultado logrado lo declaró absuelto por el Tribunal de Cuentas a D. Jacinto Navarrete en 09.09.1806. Años más tarde, en 1819 nuevamente recibieron otros escritos que ordenaban cancelarlos esta vez por el subdelegado D. José Clemente Merino. A todo esto, se suma que en el sitio en el que se encuentran ahora se ha agudizado la falta de aguas desde el año de 1797 provocando una gran mortandad de ganados y casi ninguna cosecha de granos.

También recuerda que esta propiedad rural lo compró su padre en el año de 1810 ya que no podía seguir en el rubro y actividad del comercio por su edad avanzada apostando por orientarse a la nueva actividad de labrar la tierra y dedicarse a la compra y venta de ganado vacuno. Precisa además que «a poco 
de haber vestido con dichos ganados fue asaltado en dichas haciendas por unas cuadrillas de ladrones, capitaneado por el finado Palomo, quien para robarle lo atormentaron con golpes, lo amarraron y lo dejaron en un cepo encerrado", y que por este motivo su padre al poco tiempo murió ya a una edad octogenaria y no pudo trabajar en estas haciendas por la falta de aguas y el exterminio de las reses y de toda clase de ganado. Concluyó su testimonio seńalando que a la fecha ya no tienen ganados mayores, y solo una casa en Culqui, en la que nunca sembró granos y semillas.

Prosigue la declaración de D. José Joaquín Bobadilla, natural de la ciudad de Cuenca, edad 36 ańos. Este testigo afirma que estuvo en la ciudad de Lima en el ańo de 1803 y que en esa oportunidad conoció el giro y la práctica del comercio al que se dedicaba don Sebastián Garrido, y fue en esa ocasión que lo acompañó su hijo D. Manuel, y que nuevamente en el año de 1804 se vieron juntos en la ciudad de SM de Piura, un momento en la cual Bobadilla regresó a Cuenca y a la cual también llegó $\mathrm{D}$. Sebastián Garrido practicando el giro del comercio (f.36) para de allí en adelante comprar las haciendas de Cullqui y Pillo. Tiempo después, Bobadilla regresó a la ciudad de Lima en el año de 1810 para luego retornar a la ciudad de Cuenca en 1811; nuevamente similar viaje lo realizó en 1818 para regresar a la ciudad de SM de Piura y estacionarse en el pueblo de Ayabaca, un lugar que le permitió conocer el movimiento que vivía la hacienda de Culqui y Pillo. Bobadilla afirma que estaba enterado de que esta propiedad y su dueńo habían sufrido un asalto de una cuadrilla de ladrones capitaneado por el finado Jose Sapata (a) El Palomo. Recuerda además que en los años anteriores de 1792 y 1793 quedaron exterminados el capital de ganado vacuno por el impacto de las alteraciones climáticas. Por este motivo no olvida las fuertes lluvias caídas en el año de 1791 y también las que se produjeron en los ańos de 1803 y $1804 .^{5}$

Ahora viene la declaración de D. Juan Orellana, natural de la ciudad de Cuenca, edad 23 ańos. Este sujeto recuerda la situación difícil que vivían las haciendas de Culqui y Pillo y que esto se lo informó un sambo llamado Miguel, quien trabajaba como esclavo en estas propiedades rurales asentadas en estos espacios cordilleranos.

5 César Espinoza 2019b.
En otra declaración de Pedro Regalado Sangines, edad 44 ańos, informa que el compró en el pueblo de Amaloa, provincia de Loja, un lote de ganado vacuno y que lo trasladó a la sierra de Piura para incrementar su número y del negocio ganadero. Resalta que, en 1811, don Manuel Garrido llegó a Cuenca para realizar un contrato mercantil con D. José Moreno, quien también transportaba varios esclavos y un lote de ganado vacuno a Huarmaca, pero que viviendo el tiempo de los años secos solo obtuvo pérdidas de su capital. Entonces Regalado regresó nuevamente a su hacienda de Loja pues encontró que las haciendas de Culqui y Pillo debido a la inclemencia climática estaban prácticamente abandonadas (f.41).

Esta información lo reafirma en su declaración D. Julián Abad, un habitante del sitio de Suipirá, y edad 48 años. Este recuerda que D. Sebastián Garrido trajo un lote de ganado desde la provincia de Loja (f.42). Finalmente, se presentó a declarar Juan José Masias, edad 50 años. Este añade que conoció a D. Sebastián Garrido quien se dedicaba al giro del comercio interregional, en la carrera de Cuenca-Lima y que todo lo hacía a pesar de tener una edad muy avanzada (f.44).6

\section{A modo de conclusiones preliminares}

En este ensayo se describe y reflexiona sobre la emergencia y consolidación de una sociedad de negros y negras esclavas que se incrustan con una dinámica política particular al interior de una región territorial vinculado al comercio y a la gran hacienda territorial. Al interior de esta sociedad se registran dinámicas individuales y grupales de las familias afrodescendientes, y también la movilidad y el reconocimiento social de estos grupos de color que van a asentarse en microterritorios explotando la tierra húmeda y sus pequeños capitales ganaderos. En su interacción con la sociedad blanca van a imponerse su calificación laboral y su color, mano de obra artesana y mulatos y zambos se incrustan en la vida social urbana, pero en pequeña escala. La gran mayoría de los afrodescendientes buscara otras formas de inclusión a esta sociedad borbónica que impulsa el mercantilismo

6 Sobre la región de Loja y Cuenca para los siglos XviII y xix puede consultarse a Susana Aldana 2018: 19-39; Anne-Marie Hocquenghem 2004: 23-78 y Silvia Palomeque 1990: 117-186. 
acompańado de un catolicismo rural adoptando el cimarronaje y la formación de los palenques al interior de las grandes propiedades rurales al pie de la cordillera andina como Yapatera o Morropón y en los densos y extensos campos de las grandes haciendas como Tangarará en el valle de La Chira.

En los valles de Piura y La Chira se ha conformado una sociedad multiétnica en la que los negros esclavos y libertos asumen un singular mestizaje y articulación a los negocios mercantiles y agrarios. Los zambos, negros y mulatos van a ser categorizados como miembros de la sociedad de «pardos». Negras criollas van a convivir con los mulatos, pero también con los llamados «quinterones» con tierras y ganado caprino en su afán de conseguir la libertad buscando la manumisión de sus familiares mediante la gracia de sus amos y la entrega de pequeños capitales en moneda plata de ocho reales.

La guerra que mantiene España contra UK durante el siglo XIX permitirá alcanzar pequeños espacios de la movilidad social a estos sectores subalternos que empiezan a residir en los barrios de la ciudad de SM de Piura, a convertirse en mulatos con pequeños patrimonios territoriales o de inmuebles urbanos, alcanzar la categoría de pardos beneméritos, milicianos en los batallones de Dragones y colaboradores en el combate sangriento contra las cuadrillas de bandoleros, etc.

Los Borbones y sus socios en Piura buscaran practicar una política de inclusión social planificada por la Corona y vigilada mediante decretos por el virrey Abascal y Pezuela utilizando una variedad de procedimientos administrativos y de carácter fiscal.

La burocracia imperial y virreinal mantiene sus agentes de control social representados por los subdelegados, los alcaldes y regidores, los curas y los grandes hacendados que cumplen y aplican las ordenanzas y los decretos para reproducir un sistema de control social que permita fortalecer una región dependiente de la Intendencia de Trujillo.

En este ensayo se trazan algunas pinceladas preliminares sobre la movilidad social de las castas y sus implicaciones durante el periodo colonial español y su papel en una economía regional atrapada por las fuerzas del FEN y los prolongados ciclos de años secos acompańados de prolongados y extensos incendios que abarcan el tablazo de Olmos-Sechura hasta Yapatera-Sancor-Tambogrande.
Pardos y pardas utilizaron diferentes estrategias para alcanzar la dispensa de su color y de la servidumbre doméstica. Los expedientes judiciales todavía registran un movimiento tenue de los negros esclavos para comprar su propia libertad; otros practican la estrategia de realizar servicios de milicianos o de militares a favor del rey de España para mejorar sus condiciones labores y familiares. A comienzos del siglo XIX solo un selecto grupo de pardos y mulatos libertos ligados a sus amos dueños de tierras y de grandes tiendas comerciales empezará a distinguirse y a diferenciarse de los negros esclavos viajando a otras ciudades como Guayaquil por el norte y Lima por el sur.

Casi todas las familias blancas disponen de familias de negros esclavos para el servicio doméstico y la seguridad de sus patrimonios urbanos. No faltan mujeres negras que se enamoran de blancos criollos buscando un espacio y tiempo de libertad y de vanidades materiales. Otro grupo de pardos están dedicados al trabajo artesanal, aprender a leer y a escribir y tienen oficios y profesiones manuales para el comercio local.

Un pequeño número de pardos y zambos selectos registran ocupaciones y oficios que antes estaban limitados a los blancos trabajando como plateros, alarifes, zapateros, pregoneros, etc. Un grupo de mujeres pardas se unen a negros libertos y también registran casos de mujeres que apuestan por vivir sin parejas acompańando a sus madres y abuelas, dejando sus bienes y tierras a sobrinos y sobrinas.

El estudio de la sociedad afropiurana es muy escasa en Piura y falta todavía profundizar el examen de la movilidad social y el conflicto sociorracial y político entre los grupos étnicos y la élite dominante, en el contexto de una sociedad definida por el sistema de castas. Falta impulsar estudios diacrónicos y sincrónicos, exámenes comparativos entre las poblaciones asentadas en la costa y la sierra de Huancabamba y Huarmaca.

Con motivo de la guerra del Perú contra España, en Piura se producen algunos cambios que todavía no han sido evaluados por la historiografía regional. San Miguel de Piura es una ciudad que creció entre las aguas del río Lengash y los médanos desérticos. Sus fronteras y tierras de Ejidos están rodeados por las poblaciones indígenas itinerantes que explotan las tierras húmedas y los dispersos ojos de agua o pu- 
quiales (jaguayes) existentes entre el tablazo de Payta y las tierras de labranza de la hacienda Tambogrande.

El crecimiento espacial de la ciudad de San Miguel de Piura abarca ahora cinco barrios en dirección al desierto de Payta y concentra ya más de cinco mil habitantes dispersos en los barrios del sur (Gallinacera) y el norte (Mangacheria). El impacto de las alteraciones climáticas es muy fuerte sobre esta pequeńa urbe levantada a orillas del río Lengash que temporalmente está invadida por las aguas que bajan desde los médanos de Tambogrande, Terela y Chapallirá hacia el cauce del río para nuevamente impactar en un pequeño pueblo en formación como es San Juan Bautista de Catacaos que también sufrirá la inundación temporal de su plaza y calles en formación hacia Monte Sullón y en dirección a Narigualá. La otra fuerza de la naturaleza que se despliega son los vientos y la arena que buscan cubrir a estas microurbes, a los caminos, los tambos, puentes y canales de riego que cruzan y acompañan las orillas de los ríos de Piura y las vegas de Huamará y Letirá.

La ciudad de SM de Piura está marcada por la presencia de las tinas de jabón y las fábricas de cordobanes en ambas orillas abarcando microespacios que sirven de asentamientos a las familias de negros y negras esclavas y libertas. La ciudad no puede crecer hacia el norte porque con la bajada de las aguas desde el Chipe y de la otra orilla conocida como Miraflores su crecimiento se verá limitado y ocupado por una agricultura parcelaria del panllevar y de pastos para engorde del ganado caprino y vacuno. La ciudad de Piura esta todavía rodeado de médanos y de paisajes anegadizos que ante una caída de lluvia en el verano se produce la formación de grandes lagunas que explotaran formándose grandes quebradas cuyas aguas desembocan finalmente al río por el sitio de La Legua.

En esta región, la ciudad de SM de Piura y de SF de Payta van a experimentar un lento crecimiento a partir de finales del siglo XVIII gracias al aporte de la población procedente de la migración rural y de núcleos urbanos menores y dispersos en ambas orillas de los ríos Piura y La Chira. Es una pequeña urbe cuyo crecimiento no responde a una política virreinal en lo que se refiere a un planeamiento o programa de inversiones en su infraestructura de espacios públicos. La Iglesia simboliza su presencia activa con el levantamiento de su edificio y de igual forma las órdenes religiosas, franciscanos, betlemitas y mercedarios que han levantado sus pequeñas capillas marcando sus espacios alrededor de las castas poblacionales que empiezan a convivir para enfrentar a la fuerza de la naturaleza y a los enemigos del orden social virreinal.

La ciudad comienza a servir de residencia de gente que ahora se dedica al cultivo del algodón, al negocio de la cascarilla y del aguardiente, del engorde del ganado vacuno y la reproducción del ganado mular. Se trata de una urbe que buscará responder a la expansión de los diferentes cultivos y los cambios operados en la estructura productiva de las economías provinciales que son impactados también por los ciclos del FEN y los prolongados ańos secos.

La formación de cinco barrios alrededor de una plaza central expresa entonces un proceso complejo de relocalización espacial de una población procedente de los pueblos indígenas y mestizos rurales, pero también de gente forastera que llegaría desde Loja y Cuenca, de Jaén de Bracamoros y de Trujillo. Se trata entonces de una movilización poblacional no planificada y que ha permitido la expansión de nuevas áreas urbanizadas registradas ya por Martinez de Compañon en 1784 vinculadas a capillas e iglesias cristianas. Es un tiempo de desborde de la vida social frente a lo que planeaban los borbones de imponer la continuidad en una microurbe todavía dependiente del mundo rural yunga y andino.

Estos ciclos de años de lluvias e inundaciones acompañados de prolongados ańos secos marcaron el crecimiento de una ciudad a partir de núcleos pequeńos y disgregados sobre el territorio que se van extendiendo hacia la parroquia y doctrina de los indios de San Sebastián.

En suma, estamos ante una ciudad que mantiene todavía dos barreras naturales, el rio y el tablazo desértico de Payta que abarca las tierras de las haciendas de Tambogrande y las tierras de la comunidad indígena de SJB de Catacaos.

Piura es una ciudad con una expansión urbana precaria ya que va a estar expuesta a los ataques de dos fuerzas y riesgos naturales: a) el movimiento de las aguas de los ríos y las lagunas que bajan de las nacientes cordilleranas y b) las obras culturales levantadas por los dueños de las fábricas de jabones y curtiembres. Esta situación provocará que se viva con mucho riesgo frente al desafío de la naturaleza (lluvias e inundaciones) y expuesta a su destrucción como ocurrió con el terremoto de 1814. 
En el expediente judicial revisado se registran datos orales sobre la continuidad y el impacto de las grandes lluvias y avenidas discutiendo una cronología y la magnitud del impacto en las grandes haciendas estancieras de la costa y la sierra de Piura. Con la llegada de las nuevas autoridades políticas que reemplazan al subdelegado se busca la captación de nuevos recursos materiales para proseguir la guerra contra Espańa y se impone la política de los cupos y los préstamos en dinero y bienes no solo a los dueños de las grandes propiedades de tierras y pastos sino también a los pueblos de indios y a los pequeños propietarios, colonos y labradores de la tierra.

En el expediente que examinamos, los testigos y declarantes buscan precisar una cronología de los ciclos de las alteraciones climáticas (FEN y años secos) y expresar la magnitud del daño producido que impide que los dueños puedan entregar y cancelar el «cabezón» de la alcabala y solicitar la postergación de su entrega antes y después de 1821.

Los testimonios orales recogidos nos permiten conocer el potencial peligroso que tienen los fenómenos naturales, ya sea espontáneos o manipulados dentro y fuera de la ciudad. La sociedad que vive en la provincia de Piura es vulnerable a estas fuerzas naturales pues sus estructuras de reproducción material van a ser casi destruidas por acción no solo del agua sino también del fuego y de los vientos vinculados a un tipo de economía estanciera.

Los testigos detallan el impacto y la ocurrencia del evento catastrófico sobre las poblaciones rurales, registrando como los afrodescendientes participaron en su combate llegando incluso a sacrificar sus propias vidas. Concluidos los ciclos de lluvias e inundaciones o del fuego que cruza los bosques de algarrobo y pastizales se ingresará a un ciclo social de la incertidumbre pues es muy poca la atención y apoyo técnico o monetario que ofrecen las autoridades de Trujillo o Lima.

De tal forma que ante esta incertidumbre social y la pobreza que provoca la guerra y la naturaleza, las poblaciones buscaran la forma de sobrevivir y de resistir a la dominación virreinal. La vida social se torna entonces mucho más compleja. Un sector poblacional apuesta por vivir al interior de la hacienda en calidad de peones asalariados y de campesinos colonos; los comuneros campesinos asumen la categoría laboral de yanaconas y de arrendatarios de tierras para dar forma a pequeñas poblaciones campesinas que vivirán labrando la tierra y explotando pequeños hatos de ganado vacuno y caprino con las cuales cancelar sus tributos y contribuciones fiscales. Estas familias campesinas multiétnicas vivirán formando las «ramaditas» o potreros nucleándose temporalmente para asegurar sus economías campesinas al servicio del nuevo patrón y dueño de las tierras de hacienda.

La presencia de las lluvias y las sequias afectaran a distintos grupos sociales, esta es la evidencia que intentan demostrar los testigos que participan en este proceso judicial. El uso de la memoria y la historia sirve para explicar la coyuntura sin precisar el tiempo de inestabilidad política que vivía Piura al articularse su elite y su población a la guerra contra España y su apoyo político a Tagle y San Martin.

Ahora bien, un sector de los vecinos ve la presencia de los fenómenos naturales como algo propio de la vida social y con una fatalidad incontrolable y que nada puede ya contenerlo o combatir el desastre que provocará el riesgo de vivir en las orillas de un río caudaloso cuyas aguas desembocan en las tierras y médanos de Catacaos y Sechura.

Casi nadie dice algo sobre la responsabilidad de la gente que vive en la ciudad y que ha habilitado sus fábricas y negocios imponiendo un tipo de ordenamiento espacial que va a provocar que el impacto sea mayor. Los funcionarios borbones ya no creen suficiente la idea de que la caída de las lluvias, inundaciones e incendios sean obras divinas, de la mala fortuna o la fatalidad de la vida pues buscan más información histórica de como las sociedades antiguas enfrentaron estos riesgos para recomponer la base material y recuperar la vida civilizada y de progreso. Se plantea la recuperación de viejos canales y sistemas de drenaje cuyos restos todavía se visualizan en las orillas del rio Lengash.

La ciudad de San Miguel de Piura es la población más antigua del norte del virreinato peruano. $\mathrm{Su}$ refundación en el valle de Catacaos fue realizada en 1588. En 1821 esta pequeña urbe asentada a orillas del rio Piura mantiene una posición estratégica vinculada a otra ciudad-puerto de SF de Payta rodeado de pueblos y comunidades indígenas como San Lucas de Colán y SJB de Catacaos. Desde esta posición se controla Tumbes-Parińas-Máncora por el norte y Sechura-Olmos por el sur. Esta privilegiada ubicación geográfica de la ciudad de Piura será cuestionada 
temporalmente por la llegada masiva de aguas por el rio y la caída de graves masas de agua que terminan por inundarla, de tal forma que las calles de la ciudad están construidas justamente para que el líquido elemento que se acumula en los médanos desérticos desemboque cruzando la ciudad al cauce del río Piura.

El sitio del emplazamiento de SM de Piura presenta estos inconvenientes que el negocio de las tinas de jabón la afirman mucho más a finales del siglo XVIII cuando el FEN de 1791 casi la destruye por completo.

Las nuevas poblaciones migrantes de indígenas y mestizos junto a los afrodescendientes van a posicionarse al sur y norte de la ciudad. SM de Piura es una ciudad rodeada de fábricas de tinas de jabones y de curtiembres, de camales y de pequeños esteros; su cauce se mantiene casi seco durante los años sin lluvias y son aprovechadas por los labradores de pan llevar y los pequeńos ganaderos de caprinos y mulas que la utilizan para engordar este tipo de ganado. El agua que consume la población procede de pequeńos puquiales o jaguayes y también de pozos que se construyen para disposición de lavanderas y domésticos que se estacionan durante el día. Para contener el remonte de las aguas por las orillas en la que está construido la ciudad los alcaldes de Cabildo siembran toda clase de árboles que van a tomar la forma de un pequeño malecón fronterizo que marca su crecimiento espacial y también se habilitan algunos viejos canales de agua como el de Coscomba y el Tacalá en ambas orillas rodeados de un paisaje de pastizales con isletas boscosas de algarrobo y zapote.

La ciudad está rodeada de pequeńos médanos y lomadas de arena y bosques de algarrobo que durante el tiempo de las lluvias forman numerosas lagunas que van a servir a las familias indígenas para utilizarlos para una agricultura de cultivo de granos y tubérculos temporales. En el último subcapítulo trabajamos un expediente que muestra las distintas problemáticas que generan estos períodos lluviosos para los dueños de tierras y toda clase de ganado mayor y menor.

En la ciudad de Piura se vivirá de conflictos y divisiones, de una memoria histórica que busca reducir la intensidad y la duración de estas disputas que provocan la llegada de las lluvias y las inundaciones del rio liquidando las fronteras de las haciendas y los capitales ganaderos acumulados. Las lluvias y los desbordes van a inundar la ciudad, pero también la destrucción de los potreros e invernas en la que se mantiene el capital ganadero. En la ciudad y las haciendas se van a levantar un conjunto de obras técnicas y manuales que van a bloquear las zonas y los espacios inundables, la ocupación del suelo va a provocar la modificación del comportamiento del sistema hídrico que circula en este espacio de médanos y bosques de algarrobo. $\mathrm{Al}$ interior de la ciudad de SM de Piura existe una capilla de la Virgen de las Aguas y una calle llamada «Playón» que lleva y circula el agua por la plaza central para desembocar en el rio Piura. En las haciendas y estancias ganaderas, los cercos y toda clase de madera y fierro utilizado para administrar el capital ganadero será arrastrada por las aguas y que en determinadas curvas de su recorrido y cauce va a provocar el desborde e inundación de las parcelas que conducen los labradores campesinos quienes asustados por la formación de lagunas y explosión de las quebradas buscaran refugiarse en las partes más altas del sitio de residencia.

Piura vivirá momentos graves de inundación por precipitación de las lluvias, pero también por el desborde de las aguas que trae el rio desde las nacientes cordilleranas de Morropon, Yapatera y Sancor.

En este trabajo encontramos la presencia de la población negra participando frente a los riesgos que provoca las inundaciones urbanas y rurales, laborando en los espacios anegables y participando en el combate de los incendios que se despliegan en los años de sequía.

Finalmente, señalamos que la metodología empleada para recoger los datos y reconstruir esta parte de la historia medio ambiental y social de Piura implicó la observación participante y el recorrido de la ciudad y los centros poblados rurales existentes en las nacientes cordilleranas de Yapatera y Morropon, y también de los centros poblados existentes en ambas orillas de los ríos Piura y La Chira. Se consultó imágenes satelitales, fotografías aéreas del siglo xx y se realizó la búsqueda de material documental histórica de la ocupación e inundación de estos microespacios y la consulta de planos antiguos para Catacaos y Yapatera que ahora difundimos. ${ }^{7}$

7 Véase, César Espinoza Claudio. 2019b. Proyecto Doctoral, Código NE19150066. VRIP-UNMSM, Lima, Perú. 


\section{Bibliografía}

Aguirre, Carlos (1993). Agentes de su propia libertad. Los esclavos de Lima y la abolición de la esclavitud. Lima: PUCP.

Aguirre y Charles Walker (eds.) (1990). Bandoleros, abigeos y montoneros. Criminalidad y violencia en el Perú, siglos XVIII-XX. Lima: Instituto de Apoyo Agrario/ Instituto Pasado \& Presente.

Aldana, Susana (1996). «iOcurrencias del tiempo?: Fenómenos naturales y sociedad en el Perú Colonial». En: García Acosta, ed. Historia de los desastres en América Latina. México: Ciesas; La Red, tomo 1, pp. 167-194. (1988). Empresas coloniales: las tinas de jabón en Piura. Piura: IFEA-CIPCA. (1999). Poderes en una región de frontera: comercio y familia en el norte (Piura, 1700-1830). Lima: Edic. Panaca.

Carcelén, Carlos (2009). «Historia del clima y el medio ambiente en Lima y el Perú Central, en el siglo xviII: Problema de investigación y fuentes históricas», en Revista de Historia de América, No 140. México.

Campos y Fernández de Sevilla (2014). «El obispo de Trujillo del Perú Martínez Compañón y su obra (17781788)». En: Temas de Estética y Arte (Real Academia de Bellas Artes de Santa Isabel de Hungría de Sevilla), T. XXVIII, pp. 165-212, España.

Diez Hurtado, Alejandro (2000). «Autoridades, familias y liderazgos en la costa de Piura». En Ansión, Juan; Diez, Alejandro y Mujica, Luis (edit.), pp. 91-107, Autoridad en espacios locales. Una mirada desde la antropología I Lima: PUCP.

Elias, Pavel (2004). Los señores se resisten: los caciques de Catacaos y sus estrategias de actuación y adaptación en la sociedad piurana del siglo XVII. Maestría en Estudios de la Cultura. Mención Historia Andina. Universidad Andina Simón Bolivia, Ecuador.

Espinoza Claudio, César (2019). «El virrey Abascal, los señores de tierras y los bandoleros en Piura. Anotaciones preliminares sobre la experiencia social y política de José Sapata (a) Palomo (1814-1817)». En: Investigaciones Sociales, Vol.22 N. ${ }^{\circ} 1$, pp. 195222. UNMSM/IIHS. Lima. DOI: https://doi. org/10.15381/is.v22i41.16787. (2019a). «Señores de la tierra y negros colonos en Piura y Querecotillo. Apuntes sobre la lucha por la libertad y los derechos civiles en el proceso de nacimiento de la república entre 1825-1855». En: Investigaciones Sociales, Vol.22 N.40, pp. 267-290.UNMSM-IIHS. Lima.
DOI: http://dx.doi.org/10.15381/is.v22i40.15901. (2019b). «Sociedad Indígena y negros afrodescendientes entre el absolutismo monárquico y la naciente república en Piura:1780-1850. Exploración y examen de la práctica política de los sectores populares en un espacio regional de la costa norte del Perú». Proyecto Doctoral, Código N ${ }^{\circ}$ E19150066. VRIP-UNMSM, Lima. (2017). "Joaquín de Helguero y el pensamiento económico borbónico en Piura a comienzos del siglo XIX». En: Investigaciones Sociales. Vol.21, N. ${ }^{\circ 38}$, pp.107-126. UNMSM-IIHS, Lima. (2016). «Negros y milicianos pardos en Piura durante las Cortes de Cádiz (1812-1813)». En: Investigaciones Sociales, Vol.20 N.37, pp.199-218. UNMSM-IIHS. Lima. (2016a). «Negros esclavos y segregación espacial en la sierra de Piura: siglos XviII y XIX». En: Arqueología y Sociedad, N.o 31, pp. 495-527, UNMSM, Lima. (2016b). «Los Borbones, los hacendados y la justicia real en Piura a comienzos del siglo xIx. La historia de vida de un zambo pardo y libre agobiado por sus amores, los jueces y la envidia de negros, zambos y mulatos». En: Investigaciones Sociales, Vol. 20 N. ${ }^{\circ}$ 36, pp.117-137, UNMSM-IIHS, Lima. DOI: https://doi. org/10.15381/is.v20i36.12906. (2013). «Historia regional e historia de la tierra. Anotaciones sobre el valle de La Chira, San Lucas de Colan y Amotape, siglos XVIII-XX». En: Arqueología y Sociedad, No 26, pp. 339368, UNMSM, Lima. (1999). Sociedad indigena, tierra y curacazgos yungas en la región de Piura, siglos XVI-XVII. Catacaos y los desafíos de la naturaleza, 1532-1732. Tesis de Magíster en Historia, Tomos I y II. PUCP, Lima. (1985). Piura frente al desafio de la naturaleza: 17501830. UNMSM, EAP de Historia, Lima.

Gálvez Peña, Carlos (2002). «Modernidad y piedad: notas sobre la construcción de la iglesia rural en Piura a fines del siglo XviII». En Guerra Martinière, MargaritaHolguín Callo; Oswaldo Gutiérrez Muñoz, César (edit.), pp. 581-600, Sobre el Perú: homenaje a José Agustin de la Puente Candamo. Lima: PUCP.

Hernández, Elizabeth (2007). «El marqués de Salinas, Francisco Javier Fernández de Paredes, y su permanencia en la clase dirigente piurana a inicios de la República (1785-1839)». En: BIFEA, N 36(3), pp. 361-391, Lima.

Hocquenghem Anne-Marie y Ortlieb Luc (1992). «Eventos El Niño y lluvias anormales en la costa del Perú: Siglos XVI-XIX». En BIFEA, N. 21 (1); pp. 197268. Lima. (1994). «Los españoles en los caminos del 
extremo norte del Perú en 1532». En: BIFEA, tomo 23 (1), pp. 1-67. Lima. (2004). « ¿Una posible macro región binacional andina?». En: Memorias del Seminario Taller. Hacia la elaboración de una imagen compartida de la región Sur; pp. 23-78. Ediciones Abya-Yala y Universidad Nacional de Loja, Ecuador.

Huertas, Lorenzo (2016). El nacimiento del Perú contemporáneo. Fundación de centros poblados en los Andes durante los siglos $X V$ y XVI. Lima: Fondo Editorial Universidad Ricardo Palma. (1991). «Perturbaciones étnicas en Piura». En: Boletin del Instituto Francés de Estudios Andinos, 20 (2); pp. 489-500, Lima. (1997). «Cronología y tipología de los centros poblados de la región de Piura». En: Arqueología, antropología e historia en los Andes: Homenaje a María Rostworowski. Lima: Instituto de Estudios Peruanos-Banco Central de Reserva del Perú, p. 471-486.

Huertas, Lorenzo (2009). Injurias del tiempo. Lima: Editorial Universitaria, Universidad Ricardo Palma.

Huertas, Lorenzo (2001). Diluvios andinos a través de las fuentes documentales. Lima: Pontificia Universidad Católica del Perú.

Jaramillo BaAnante, Miguel (1998). "El comercio de la cascarilla en el norte peruano-sur ecuatoriano: evolución e impacto regional de una economía de exportación, 1750-1796». En: Scarlett OrPhelan Godoy et Yves Saint-Geours. El norte en la historia regional, siglos XVIII-XIX; pp. 51-90. Lima: IFEA-CIPCA.

Kapsoli, Wilfredo (2014). «Esclavitud en el Perú». En: Tradición N. ${ }^{\circ}$ 14, pp. 63-70. Lima: Universidad Ricardo Palma.

KLEIN, Herbert S. (2016). «La experiencia afroamericana en perspectiva comparada: la cuestión actual del debate sobre la esclavitud en las Américas». En: TEMPUS, pp. 308-332, Medellín.

Mabres, Antonio; Woodman Ronald y Zeta Rosa (1993). «Algunos apuntes históricos adicionales sobre la cronología de El Niño». BIFEA 22 (1); pp. 395-406; Lima.

Macera, Pablo (1963). Historia del petróleo peruano: las breas coloniales del siglo XVIII. 36 pp. Lima: UNMSM.

Ministerio de Cultura (2019). Encuentro de Investigadores sobre Cultura Afroperuana 2018. Lima.

Navarro, P. José y otros (1991). Vida y obra del obispo Baltasar Jaime Martinez Compañón. Piura: Universidad de Piura.

Ortlieb, Luc y Hocquenghem, Anne-Marie (2001). «Reconstrucción del Registro Histórico de Eventos El
Niño en el Perú: un Estado de avance». En J. Tarazona y otros, El Niño en América Latina. Lima: Consejo Nacional de Ciencia y Tecnología.

Palomeque, Silvia (1990). Cuenca en el siglo XIX. La articulación de una región. Quito: FLACSO-Ecuador, Abya-Yala.

Paz Velásquez, Juan (2014). Ayeres de Huancabamba. Piura, Perú. En: http://www.ugelhuancabamba. gob.pe/images/stories/ayeres-de-huancabamba.pdf. Consultado en 01.12.2018. (2013). Huancabamba, la Comunidad ancestral de Segunda y Cajas. Piura.

Pino, Fermín del (2012). «La labor 'histórica' del obispo Martínez Compañón en Trujillo, a través de su sobrino José Ignacio de Lecuanda». En Ignacio Arellano y Carlos Mata Indurain (Eds.), El obispo Martínez Compañón. Vida y obra de un navarro ilustrado en América; pp. 421-508. Pamplona, Espańa: Gobierno de Navarra.

Pinheiro Rodrigues, Bruno (2016). «Liberdade para ser conquistada: a instituiçáo escravista no Alto Peru e a luta pela liberdade (séculos XviII e XIx)». En: Revista Latino-Americana de História; Vol. 5, N. ${ }^{\circ}$ 16; pp. 2236, Dezembro, Universidade do Vale do Rio dos Sinos - UNISINOSm Brasil.

Ramírez Adrianzén, Miguel Justino (1966). Huancabamba: su historia, su geografia, su folklore. Lima: Ministerio de Hacienda y Comercio.

Rocha, Arturo (2019). El Meganiño de 1791 en el Perú y el mundo. http://www.imefen.uni.edu.pe/Temas_interes/ROCHA/Meganino_de_1791_en_el_Peru_y_el_ mundo.pdf. Consultado en 12.12.2019.

SeINer, Lizardo (2002). Estudios de historia medioambiental: Perú, siglos XVI-XX. Universidad de Lima. (2001). «El fenómeno El Niño en el Peru: reflexiones desde la historia». En: Debate Agrario, N 33, pp.1-18, CEPES, Lima.

Tardieu, Jean-Pierre (2018). El Negro Guillermo, Venezuela (1769-1771). Sevilla: Ediciones Alfar. (2004). El decreto de Huancayo. La abolición de la esclavitud en el Perú, 3 de diciembre de 1854. Lima: Fondo Editorial del Congreso del Perú.

Vega, Juan José (1993). Pizarro en Piura. Piura: Instituto Cambio y Desarrollo.

Vegas Vélez, Manuel (1997). «El Niño y sus ocurrencias en Piura». En: Bruno Revesz et al. Piura: Región y Sociedad. pp. 88-114. Lima: CIPCA-CBC. 